OPEN ACCESS

Edited by:

Mar Benavides,

Institut de Recherche Pour le

Développement (IRD), France

Reviewed by:

Ulisse Cardini,

Stazione Zoologica Anton Dohrn

Napoli, Italy

Valentine Meunier,

Institut de recherche pour le développement (IRD), New Caledonia

${ }^{*}$ Correspondence: Jiayuan Liang jyliang@gxu.edu.cn Kefu Yu

kefuyu@scsio.ac.cn orcid.org/0000-0003-3409-9945

Specialty section:

This article was submitted to

Aquatic Microbiology,

a section of the journal

Frontiers in Microbiology

Received: 30 August 2021 Accepted: 11 November 2021 Published: 17 December 2021

Citation:

Ge R, Liang J, Yu K, Chen B, Yu X, Deng $C$, Chen J, Xu Y and

Qin L (2021) Regulation of the

Coral-Associated Bacteria and Symbiodiniaceae in Acropora valida Under Ocean Acidification.

Front. Microbiol. 12:767174. doi: 10.3389/fmicb.2021.767174

\section{Regulation of the Coral-Associated Bacteria and Symbiodiniaceae in Acropora valida Under Ocean Acidification}

\author{
Ruiqi Ge ${ }^{1}$, Jiayuan Liang ${ }^{1,2 *}$, Kefu Yu ${ }^{1,2 *}$, Biao Chen ${ }^{1}$, Xiaopeng $\mathrm{Yu}^{1}$, Chuanqi Deng ${ }^{1}$, \\ Jinni Chen ${ }^{1}$, Yongqian $\mathrm{Xu}^{1}$ and Liangyun Qin ${ }^{1}$
}

${ }^{1}$ Guangxi Laboratory on the Study of Coral Reefs in the South China Sea, Coral Reef Research Center of China, School of Marine Sciences, Guangxi University, Nanning, China, ' Southern Marine Science and Engineering Guangdong Laboratory (Zhuhai), Zhuhai, China

Ocean acidification is one of many stressors that coral reef ecosystems are currently contending with. Thus, understanding the response of key symbiotic microbes to ocean acidification is of great significance for understanding the adaptation mechanism and development trend of coral holobionts. Here, high-throughput sequencing technology was employed to investigate the coral-associated bacteria and Symbiodiniaceae of the ecologically important coral Acropora valida exposed to different $\mathrm{pH}$ gradients. After 30 days of acclimatization, we set four acidification gradients $(\mathrm{pH} \mathrm{8.2,} \mathrm{7.8,} \mathrm{7.4,} \mathrm{and} \mathrm{7.2,}$ respectively), and each $\mathrm{pH}$ condition was applied for 10 days, with the whole experiment lasting for 70 days. Although the Symbiodiniaceae density decreased significantly, the coral did not appear to be bleached, and the real-time photosynthetic rate did not change significantly, indicating that $A$. valida has strong tolerance to acidification. Moreover, the Symbiodiniaceae community composition was hardly affected by ocean acidification, with the $\mathrm{C} 1$ subclade (Cladocopium goreaui) being dominant among the Symbiodiniaceae dominant types. The relative abundance of the Symbiodiniaceae background types was significantly higher at $\mathrm{pH} 7.2$, indicating that ocean acidification might increase the stability of the community composition by regulating the Symbiodiniaceae rare biosphere. Furthermore, the stable symbiosis between the $\mathrm{C} 1$ subclade and coral host may contribute to the stability of the real-time photosynthetic efficiency. Finally, concerning the coralassociated bacteria, the stable symbiosis between Endozoicomonas and coral host is likely to help them adapt to ocean acidification. The significant increase in the relative abundance of Cyanobacteria at $\mathrm{pH} 7.2$ may also compensate for the photosynthesis efficiency of a coral holobiont. In summary, this study suggests that the combined response of key symbiotic microbes helps the whole coral host resist the threats of ocean acidification.

Keywords: Symbiodiniaceae, coral-associated bacteria, coral holobiont, ocean acidification, photosynthetic efficiency 


\section{INTRODUCTION}

Since the Industrial Revolution, the concentration of atmospheric $\mathrm{CO}_{2}$ has continuously increased. As the most significant carbon pool on the earth, the ocean has continuously absorbed $\mathrm{CO}_{2}$ from the atmosphere, causing the $\mathrm{pH}$ of the surface seawater to drop and consequently, promoting ocean acidification, which is one of the biggest threats to the global coral reef ecosystem (Hoegh-Guldberg et al., 2007). Ocean acidification affects the photosynthesis, calcification, growth, and survival of coral reef (Albright and Langdon, 2011). Moreover, it also reduces the calcification of reef-building corals by changing the chemical composition of seawater carbonates (Leclercq et al., 2002; Kroeker et al., 2010), and changes in $\mathrm{CO}_{2}$ content in seawater affect coral photosynthesis to varying degrees (Comeau et al., 2017; Kenkel et al., 2018). Ocean acidification can also lead to changes in the community structure of coral-associated bacteria, thereby affecting the physiological characteristics of the coral host (Thurber et al., 2009; Meron et al., 2011). The fourth report of the Intergovernmental Panel on Climate Change (IPCC) in 2007 focused on the adverse effects of ocean acidification on corals and other calcareous organisms (Mingle, 2020). The report titled "The ocean and cryosphere in a changing climate," released by the IPCC in 2019, further pointed out that ocean acidification and other environmental pressures have impacted the distribution and abundance of marine organisms (Mingle, 2020). Hence, if $\mathrm{CO}_{2}$ emissions continue to increase, the existing coral reef ecosystems will face survival problems by the end of the 21st century (Ricke et al., 2013).

As a mutual symbiont assemblage, coral holobiont includes Symbiodiniaceae, bacteria, fungi, archaea, and other microorganisms (Bourne et al., 2016; LaJeunesse et al., 2018). Symbiodiniaceae is an essential part of the coral holobiont, as they fix carbon through photosynthesis and provide up to $95 \%$ of the energy requirements of the host coral (Muscatine and Cernichiari, 1969; Steen and Muscatine, 1984; Muscatine et al., 1989; Rädecker et al., 2015). Coral-associated bacteria are the most basic and active part of the coral holobiont. They play an essential role in the circulation and transportation of nutrients including carbon, nitrogen, sulfur, phosphate, and trace metal elements (Bourne et al., 2016). Noteworthy, the diversity and distribution characteristics of coral holobionts are easily affected by changes in the surrounding environment (Ben-Haim et al., 2003; Bourne and Munn, 2005; Bourne et al., 2008). Thus, rising sea temperature, ocean acidification, and nutrient changes affect the composition of coral holobionts, thereby affecting the health of corals.

Several studies addressed the impact of high-temperature stress on coral holobionts (Thurber et al., 2009; Yu et al., 2020, 2021), whereas relatively few studies investigated the impact of ocean acidification on coral holobionts. Furthermore, the research on coral holobiont by ocean acidification has mainly focused on bacteria, which demonstrated that ocean acidification affects the community composition of adult coralassociated bacteria (Meron et al., 2011; Morrow et al., 2015; O'Brien et al., 2016; Meunier et al., 2021), which will further affect the acidification tolerance of the coral (Liang et al., 2017;
Torda et al., 2017). Meron et al. (2011) found that the diversity of Acropora eurystoma-associated bacteria significantly increased when seawater $\mathrm{pH}$ dropped from 8.2 to 7.3. The number of bacteria related to disease and stress, such as Rhodobacter sp., Bacteroidetes sp., and Proteobacteria, increased. The study by Thurber et al. (2009) also highlighted that the diversity of Porites compressa-associated bacteria fluctuates sharply under a low $\mathrm{pH}$ environment ( $\mathrm{pH}$ 6.7). Including the emergence of viral lysogen-related stress response genes, the relatively rare Bacteroidetes increased by 14 times at $\mathrm{pH} 6.7$ and Crenarchaeota increased by three times. These studies have shown that ocean acidification can lead to changes of the community composition in the coral-associated bacteria. However, the effects of ocean acidification on Symbiodiniaceae remain poorly understood (Goiran et al., 1996; Reynaud et al., 2003). Previous studies showed that ocean acidification decreases Symbiodiniaceae density and affects its photosynthetic efficiency (Krief et al., 2010; Comeau et al., 2017).

Herein, a laboratory-based simulation experiment was used to analyze the community dynamics and physiological changes of key symbiotic members (Symbiodiniaceae and bacteria) in an environmentally sensitive branch coral (A. valida) exposed to seawater with different $\mathrm{pH}$ values $(\mathrm{pH} 8.2,7.8,7.4$, and 7.2). This study aimed to reveal the changes in the community composition of coral-associated bacteria and Symbiodiniaceae under ocean acidification and provide a more comprehensive understanding of their impact on coral reef ecosystems.

\section{MATERIALS AND METHODS}

\section{Coral Collection}

Acropora valida in good growth conditions was collected from the coral communities of Weizhou Island in the Beibu Gulf at a depth of $6 \mathrm{~m}$, with an individual size of approximately $15 \mathrm{~cm}$ in diameter. A total of five coral colonies were collected, each separated by a distance greater than $2 \mathrm{~m}$, and were quickly transferred to a foam box filled with seawater $\left(26^{\circ} \mathrm{C}\right)$. The samples were transported to the Coral Reef Research Center of Guangxi University within $24 \mathrm{~h}$. Then, each coral colony was cut into four nubbins on average, and they were acclimatized in an aquarium tank for 1 month. The domestication conditions included the use of a breeding tank with a size of $600 \mathrm{~mm} \times 600 \mathrm{~mm} \times 600 \mathrm{~mm}$ (length $\times$ width $\times$ height) to maintain a stable water environment with the following characteristics: water flow, $6,500 \mathrm{~L} / \mathrm{h}$; color temperature, $15,000 \mathrm{~K}$ (daily daytime 6:00-18:00, given $12 \mathrm{~h}$ of light); salinity, $35 \mathrm{~g} / \mathrm{L}, \mathrm{pH}$ 7.5-8.0; $\mathrm{Ca}^{2+}$ concentration, 380-450 ppm; $\mathrm{Mg}^{2+}$ concentration, 1,200$1,320 \mathrm{ppm}$; and water temperature, $26^{\circ} \mathrm{C}$. During the entire transportation process, the coral samples were transported indoors within $24 \mathrm{~h}$ in an incubator filled with seawater, with little disturbance.

\section{Experimental Setup}

After 30 days of cultivation, a new growing point appeared on top of the coral branch, indicating that the individual coral was adapted to the environment of the experimental aquaculture 
tank and that acidification experiments could be performed. The controlled variable method was used, with $\mathrm{pH}$ as a single variable, to keep other water quality parameters stable during the experiment. The ocean acidification simulation system (OA-simulated system, OASys) designed by Zheng et al. (2018), which adjusts the $\mathrm{pH}$ of the water by controlling the highpurity $\mathrm{CO}_{2}$ injected into the seawater tank, was used to adjust the $\mathrm{pH}$ of the experimental water. A pole transducer was used to detect the $\mathrm{pH}$ value $( \pm 0.01 \mathrm{pH}$ unit), which was set to

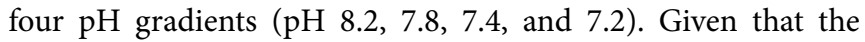
$\mathrm{pH}$ of the water measured before acidification fluctuated at a $\mathrm{pH}$ range of $8.1-8.3$ between daytime and nighttime, a $\mathrm{pH}$ of 8.2 was set as the normal seawater $\mathrm{pH}$ (control group), and each $\mathrm{pH}$ gradient was maintained for 10 days. Five biological replicate colonies were collected for DNA extraction and Symbiodiniaceae density measurement on the last day of each $\mathrm{pH}$ gradient. The extracted DNA samples were used for subsequent high-throughput sequencing.

\section{Chlorophyll Fluorescence Detection}

To detect the influence of environmental factors on the photosynthetic efficiency of coral holobionts, the ultra-portable modulated chlorophyll fluorometer Mini-PAM (Walz Heinz $\mathrm{GmbH}$, Effeltrich, Germany) was used to measure the chlorophyll fluorescence parameters. When measuring, the Mini-PAM optical fiber probe was placed at a vertical distance of approximately $2 \mathrm{~mm}$ from the coral surface. The effective optical path of the optical fiber was $5.5 \mathrm{~mm}$, and the electrical signal damping and gain were set to 1 and 2 , respectively. Under the daylight simulation of each $\mathrm{pH}$ gradient, the realtime photosynthetic efficiency, computed as $\left(F_{\mathrm{m}}{ }^{\prime}-F_{\mathrm{t}}\right) / F_{\mathrm{m}}{ }^{\prime}\left(F_{\mathrm{t}}\right.$ means real-time fluorescence), was measured at the same time to ensure that the measurement time of each $\mathrm{pH}$ gradient was the same.

\section{Symbiodiniaceae Density and Community Composition Analysis}

To determine the Symbiodiniaceae density, a Waterpik instrument equipped with sterile seawater was used to rinse the coral surface thoroughly. Then, the rinsing fluid was collected, its volume was recorded with a graduated cylinder, and $4 \mathrm{ml}$ was centrifuged at $4^{\circ} \mathrm{C}, 4,000 \mathrm{rpm}$ for $5 \mathrm{~min}$. The supernatant was removed, and $200 \mu \mathrm{l}$ of $4 \%$ formaldehyde was added to fix the Symbiodiniaceae for later analysis (Shu et al., 2011; Qin et al., 2019). The Symbiodiniaceae fixed on a hemocytometer were observed and counted under an optical microscope. The surface area of the coral tissue was determined according to the correlation between the weight of the foil paper and surface area (Shu et al., 2011).

The Symbiodiniaceae community composition analysis was performed according to the following steps (Chen et al., 2020): Sterile surgical scissors were used to cut the coral samples (about $90 \mathrm{mg}$ ) containing the coral tissue, skeleton, and mucus, with five parallel samples at each $\mathrm{pH}$ gradient; (2) the Marine Animal Genomic DNA Extraction Kit (TIANGEN, DP324) and Plant Genomic DNA Kit (OMEGA, D3485-2) were used to extract the DNA of coral, and coral-associated bacteria and Symbiodiniaceae, respectively. Mixed animal DNA samples and plant DNA samples, and screened for quality and purity; (3) using forward ITS2 (5'-GAATTGCAGAACTCCGTG-3') and reverse ITS2 (5'-GGGATCCATATGCTTAAGTTCAGCGG GT-3') as primers, PCR amplification was performed on the rDNA Symbiodiniaceae ITS2 region. The reaction was performed in a $20 \mu \mathrm{l}$ system (TransGen ${ }^{\circledR}$ AP221-02; TransGen Biotech, Beijing, China): $4 \mu \mathrm{l}$ of $5 \times$ Fast $P f u$ buffer, $2 \mu \mathrm{l}$ of $2.5 \mathrm{mM}$ deoxyribonucleotide triphosphates (dNTPs), $0.8 \mu \mathrm{l}$ of the forward primer $(5 \mu \mathrm{M}), 0.8 \mu \mathrm{l}$ of the reverse primer $(5 \mu \mathrm{M}), 0.4 \mu \mathrm{l}$ of Fast Pfu Polymerase, $10 \mathrm{ng}$ of the DNA template, and $\mathrm{dd}_{2} \mathrm{O}$ to adjust the final volume $(20 \mu \mathrm{l})$. The PCR amplification program was: $94^{\circ} \mathrm{C}$ pre-denaturation for $3 \mathrm{~min}$, and $35 \mathrm{cycles}$ (denaturation at $94^{\circ} \mathrm{C}$ for $30 \mathrm{~s}$, annealing at $55^{\circ} \mathrm{C}$ for $30 \mathrm{~s}$, and extension at $72^{\circ} \mathrm{C}$ for $45 \mathrm{~s}$ ), and extension at $72^{\circ} \mathrm{C}$ for $10 \mathrm{~min}$; and (4) the duplicate samples were merged and were submitted to Biomarker Technologies Co., Ltd. (Beijing, China) for sequencing on the Illumina MiSeq $(\mathrm{PE} 2 \times 300)$ platform (Illumina, San Diego, CA, United States).

Trimmomatic software was used to perform quality control on the Illumina MiSeq platform (Bolger et al., 2014). Reads were truncated at an average quality score $<20$ to ensure highquality reads for subsequent analysis. Used the combined data to obtain a full-length ITS2 rDNA fragment (Zhang et al., 2014), trimmed the read quality, and used Mothur (version 1.34.4) to check the chimeras. Cutadapt (version 1.1) was used to trim the reverse and forward primer sequences (Ziegler et al., 2017). Since the previous ITS2 database contained some repetitive sequences, several published databases were collected (Franklin et al., 2012; Arif et al., 2014; Tong et al., 2017; Ziegler et al., 2017; Chen et al., 2019), and BLASTn was used to compare all sequences with those stored in the ITS2 database (Tong et al., 2017). In addition, to query ITS2 data at different resolutions and facilitate comparison with the results of denaturing gradient gel electrophoresis, to avoid the interference of intragenomic variation, the number of different ITS2 sequences that were present at a minimum cutoff $\geq 1 \%$ in at least one of the 20 samples was evaluated (Ziegler et al., 2017).

\section{Bacterial Community Analysis}

Using the total genomic DNA sample as a template, the forward primer 27F [5'-AGAGTTTGATC (C/A) TGGCTCAG-3'] and the reverse primer 1492R [5'-TACGG $(\mathrm{C} / \mathrm{T})$ TACCTTGTTACGAC-3'] were used for the PCR amplification of the full-length of the bacterial $16 \mathrm{~S}$ rRNA (ABI GeneAmp ${ }^{\circledR}$ 9700; Thermo Fisher Scientific, Waltham, MA, United States; Singer et al., 2016). The PCR expansion reaction was performed in a $20 \mu \mathrm{l}$ system: $4.5 \mu \mathrm{l}$ of $5 \times$ Fast $P f u$ buffer, $2.5 \mu \mathrm{l}$ of $2.5 \mathrm{mM}$ dNTPs, $0.6 \mu \mathrm{l}$ of the forward primer $(5 \mu \mathrm{M}), 0.6 \mu \mathrm{l}$ of the reverse primer $(5 \mu \mathrm{M}), 0.6 \mu \mathrm{l}$ of Fast $P f u$ polymerase, $0.3 \mu \mathrm{l}$ of BSA, $10 \mathrm{ng}$ of the template DNA, and $\mathrm{ddH}_{2} \mathrm{O}$ to adjust the final volume $(20 \mu \mathrm{l})$. The $\mathrm{PCR}$ amplification program was: $95^{\circ} \mathrm{C}$ pre-denaturation for $5 \mathrm{~min}$ and 30 cycles (denaturation at $95^{\circ} \mathrm{C}$ for $30 \mathrm{~s}$, annealing at $55^{\circ} \mathrm{C}$ for $30 \mathrm{~s}$, and extension at $72^{\circ} \mathrm{C}$ for $90 \mathrm{~s}$ ), and extension at $72^{\circ} \mathrm{C}$ for $7 \mathrm{~min}$. For the gel recovery and purification, elution, detection, and quantification of the 
PCR products, $2 \%$ agarose gel electrophoresis, AxyPrep DNA kit, Tris- $\mathrm{HCl}, 2 \%$ agarose electrophoresis, and QuantiFluorTM-ST fluorescence quantification system (Promega, Madison, WI, United States) were used, respectively. The duplicate samples were merged and used for sequencing (BioMarker, Beijing, China) on the Illumina MiSeq (PE $2 \times 300$ ) platform.

The sequence was divided into Operational taxonomic units (OTU) at a similarity level of $97 \%$, and the PE reads were spliced, merged, quality controlled, and filtered with reference to the Ribosomal database project used by Liang et al. (2017). The composition and number of bacterial communities in different taxonomic levels (phyla and genus) of each sample were obtained through OTU cluster analysis and species taxonomy analysis. Mothur (Schloss et al., 2011) was used to perform alpha diversity index analysis on sample clustering results to obtain single sample diversity (alpha diversity) through Good's species coverage (Coverage), community richness (Ace), and community diversity (Shannon) index, reflecting the coverage, abundance, and diversity of the microbial communities. Qiime (Kuczynski et al., 2011) was used to calculate the beta diversity distance matrix. Vegan software performed principal coordinates analysis ( $\mathrm{PCoA}$ ) and revealed the structure of bacterial communities in different groups, and PERMANOVA was used to test the significant differences in bacterial community structure between groups. The linear discriminant analysis effect size (LEfSe) method was used to identify shifts in the abundance of bacterial OTUs among different $\mathrm{pH}$ gradients. The significance threshold was set to LDA value $>4.0$ and $p<0.05$ (Segata et al., 2011).

\section{Statistical Analysis}

The SPSS Statistics 19 (IBM Corp., Armonk, NY, United States) was used to perform one-way ANOVA on the real-time photosynthetic efficiency data of the experimental gradient and the Symbiodiniaceae density data of each $\mathrm{pH}$ gradient, and Duncan was used for the post hoc test. The Kruskal-Wallis test was used to analyze the significant difference in Symbiodiniaceae distribution and bacterial community composition in each $\mathrm{pH}$ gradient.

\section{RESULTS}

\section{Apparent Morphological Changes of A. valida}

As the $\mathrm{pH}$ of seawater decreased, the apparent morphology of A. valida changed, as visible to the naked eye (Figure 1). At $\mathrm{pH} 8.2$ and 8.0, the color of A. valida was dark brown, and its tentacles were freely stretched. When the $\mathrm{pH}$ turned to 7.4-7.8, the color of A. valida became light brown, and when the $\mathrm{pH}$ value became lower $(\mathrm{pH}$ 7.2), the color of the coral did not change further, and the coral tentacles could still stretch freely and actively. Acropora valida did not appear to be bleached during the experiment when the seawater was acidified from $\mathrm{pH} 8.2$ to 7.2 , and holobionts thus appear to have a strong acid resistance.

\section{Changes in Symbiodiniaceae Density and Real-Time Photosynthetic Efficiency}

As shown in Figure 2A, the density of Symbiodiniaceae changed significantly with the decrease in seawater $\mathrm{pH}$ (ANOVA, $F=21.325, p<0.005$, post hoc: Duncan). When the $\mathrm{pH}$ of the seawater was 8.2 , the average density of Symbiodiniaceae was $1.15 \pm 0.50 \times 10^{6}$ cells cm$^{-2}$. At $\mathrm{pH} 7.8$, the Symbiodiniaceae density significantly decreased to $0.77 \pm 0.46 \times 10^{6} \mathrm{cells} \mathrm{cm}^{-2}$. At $\mathrm{pH}$ 7.4, the Symbiodiniaceae density continued to drop to $0.38 \pm 0.42 \times 10^{6} \mathrm{cells} \mathrm{cm}^{-2}$ and at $\mathrm{pH} 7.2$ was of $0.22 \pm 0.16 \times 10^{6} \mathrm{cells} \mathrm{cm}^{-2}$, which was only $19 \%$ of the density at $\mathrm{pH}$ 8.2. Thus, the density of Symbiodiniaceae in A. valida fluctuated significantly under the influence of ocean acidification. As the $\mathrm{pH}$ gradient dropped, the density of Symbiodiniaceae in the corals decreased significantly. However, as shown in Figure 2B, the real-time photosynthetic efficiency value measured at $\mathrm{pH} 7.8$ was the highest, with an average value of $0.6296 \mu \mathrm{mol} \cdot \mathrm{m}^{-2} \cdot \mathrm{s}^{-1}$, and the lowest was measured at $\mathrm{pH} 7.2$, with an average value of $0.6050 \mu \mathrm{mol} \cdot \mathrm{m}^{-2} \cdot \mathrm{s}^{-1}$, showing that acidification had no significant effect on the real-time photosynthetic efficiency of coral (ANOVA, $F=1.217, p=0.302$, post hoc: Duncan).

\section{Composition of Symbiodiniaceae}

The community composition of the Symbiodiniaceae in 20 coral samples was evaluated under four $\mathrm{pH}$ gradients $(\mathrm{pH}$ 8.2, $7.8,7.4$, and 7.2). The composition of the family group was analyzed by PCoA based on the OTU levels, wherein the first and the second principal components (PC1 and PC2), which accounted for 44 and $22 \%$ of the overall variance variation, showed the differences in the community composition of Symbiodiniaceae under different $\mathrm{pH}$ conditions (Figure 3A). In total, the community composition of the Symbiodiniaceae group had significant differences under the different $\mathrm{pH}$ gradients (PERMANOVA, $p=0.001$ ).

The composition of Symbiodiniaceae subclades showed that A. valida is associated with many species of Symbiodiniaceae, including $\mathrm{C} 1, \mathrm{C} 1 \mathrm{ca}, \mathrm{C} 1 \mathrm{p}, \mathrm{C} 72$, Cspc, C1c.C45, C18, C18, C44, and $\mathrm{C} 70$ (Figure 3B), of which the $\mathrm{C} 1$ subclade had an absolute advantage. Overall, except for the presence of $\mathrm{C} 70$ in the dominant types at $\mathrm{pH} 7.8$ and 7.4, the composition of the Symbiodiniaceae dominant types in A. valida was hardly changed during the entire acidification process. The difference analysis showed that the relative abundance of C70 increased significantly when the $\mathrm{pH}$ dropped from 8.2 to 7.8 (KruskalWallis, C70: $H=16.269, p=0.001$, post hoc: Duncan), which increased from the background types to the dominant types. When the $\mathrm{pH}$ reached 7.4, the average relative abundance of $\mathrm{C} 70$ was $2.62 \%$. When the $\mathrm{pH}$ dropped to 7.2 , the relative abundance of C70 dropped below $1 \%$, accounting for only $0.001 \%$. Under the condition of $\mathrm{pH} 7.2$, the relative abundance of $\mathrm{C} 1$ subclade dropped significantly to $76.44 \%$ (Kruskal-Wallis, C1: $H=14.657, p=0.002$, post hoc: Duncan), whereas those of the background types (Figure 3B: Others) rose significantly to $8.27 \%$ (Kruskal-Wallis, Others: $H=16.211, p=0.001$, post hoc: Duncan). 


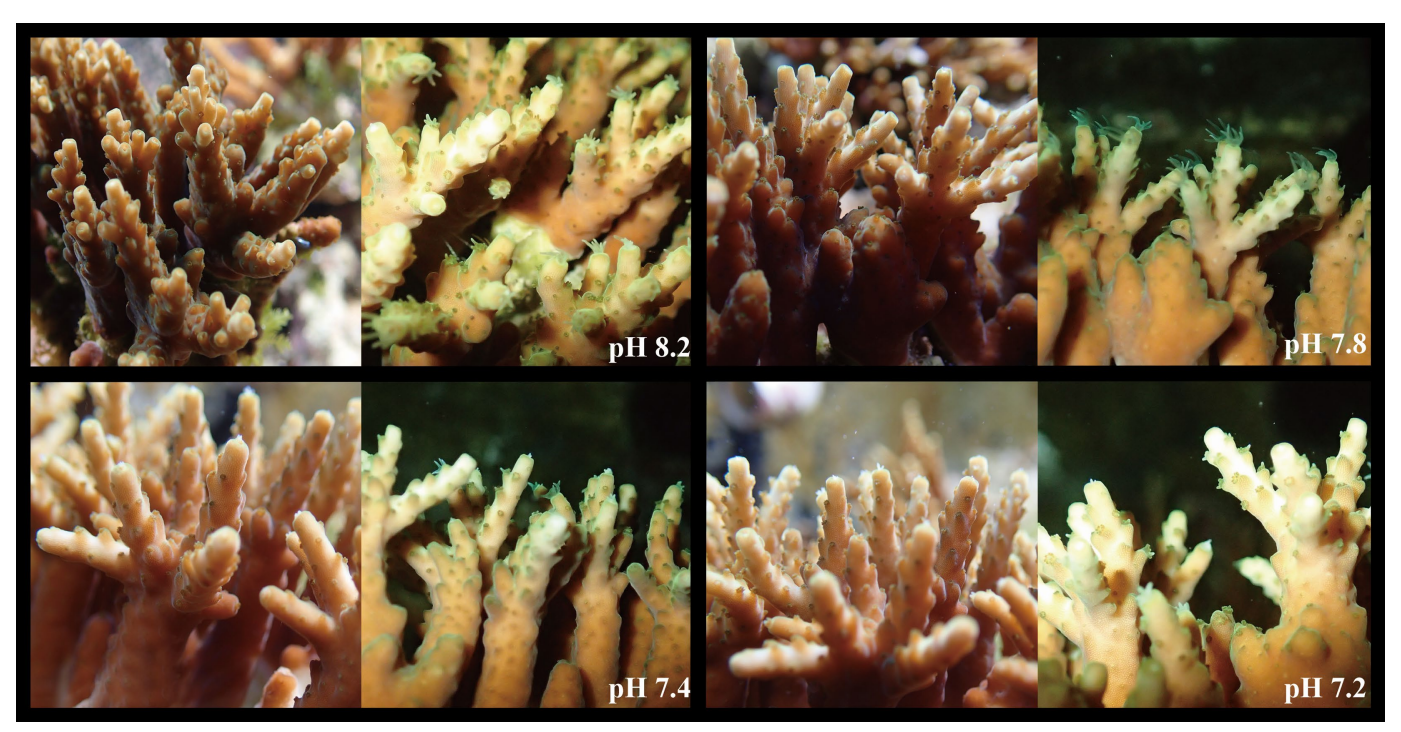

FIGURE 1 | Changes of apparent coral morphology under different $\mathrm{pH}$ gradients (two photos for each $\mathrm{pH}$ gradient, the left side were taken in simulated daylight, and the right side were taken at night).
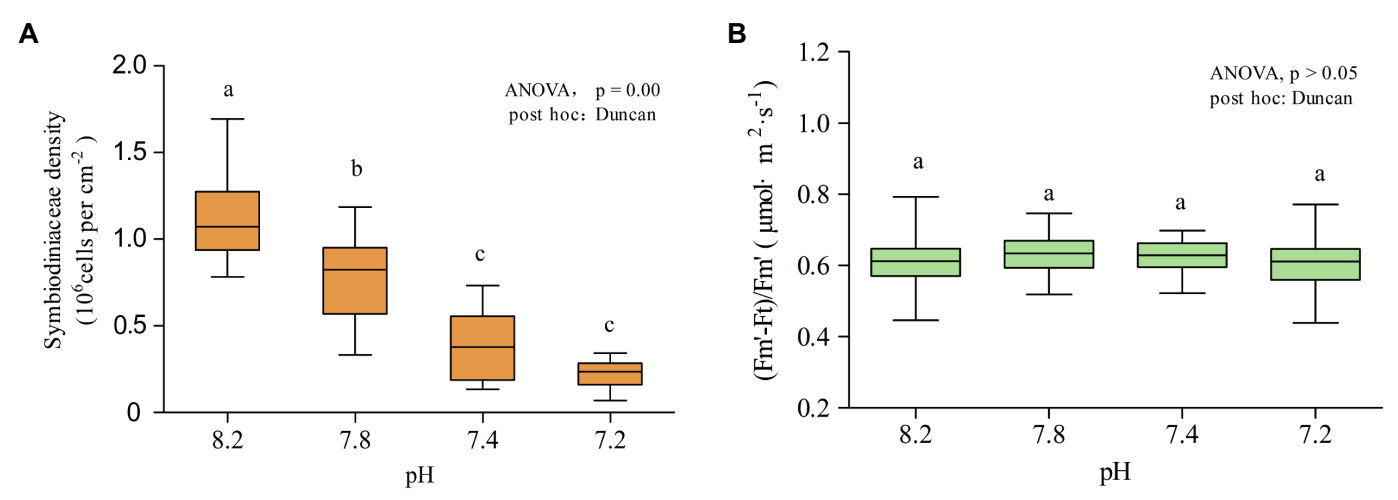

FIGURE 2 | Symbiodiniaceae density and chlorophyll fluorescence at different $\mathrm{pH}$ gradients. Each pH condition lasted 10 days. (A) Density of Symbiodiniaceae. (B) $\left(F_{\mathrm{m}}{ }^{\prime}-F_{\mathrm{t}}\right) / F_{\mathrm{m}}{ }^{\prime}$. Lower case letters $(\mathrm{a}, \mathrm{b}, \mathrm{c})$ denote differences by Duncan post hoc test.

\section{Changes in the Community Composition of Coral-Associated Bacteria}

We performed a coral-associated bacterial community composition analysis on the 20 samples under the four different $\mathrm{pH}$ gradients ( $\mathrm{pH} 8.2,7.8,7.4$, and 7.2). Twenty sample databases were obtained from the high-throughput sequencing for a total of 154,320 sequence numbers, and the sequence length was $1,000-1,800 \mathrm{bp}$. The number of sequences in each sample was more than 6,036 , and the coverage index was greater than $99.8 \%$, indicating that the sequencing coverage of each sample could genuinely reflect the actual situation of the coral-associated bacteria. Species annotation analysis detected a total of 10 bacterial phyla, 13 classes, 44 orders, 65 families, 86 genera, and 68 species, wherein the number of species was less than that of the genera because some species could be annotated to the genus level in the database, and there was no annotation information at the species level. Moreover, 165 OTU clusters were detected. Figures 4A,B show the changes in the alpha diversity indices of the four groups of coral samples. At the OTU level, the four $\mathrm{pH}$ gradients had no significant differences in the Chaol index. Among them, the coral-associated bacterial community had the highest abundance at $\mathrm{pH}$ 7.4. A significant difference in the bacterial community diversity (Shannon) between $\mathrm{pH} 8.2$ and 7.8 was observed (Student's $t, p<0.05$ ), and the differences in the Shannon indices between the $\mathrm{pH} 7.2$ and 7.8 groups were also significant (Student's $t, p<0.01$ ). At $\mathrm{pH} 7.2$, the bacteria community associated with $A$. valida had the highest diversity.

In the PCoA based on the OTU level, wherein PC1 accounted for $15.94 \%$ of the overall variance variation, the results showed the community composition of the coral-associated bacteria under the different $\mathrm{pH}$ conditions (Figure 4C). At $\mathrm{pH} 7.4$, the degree of dispersion among the samples was the largest; that 

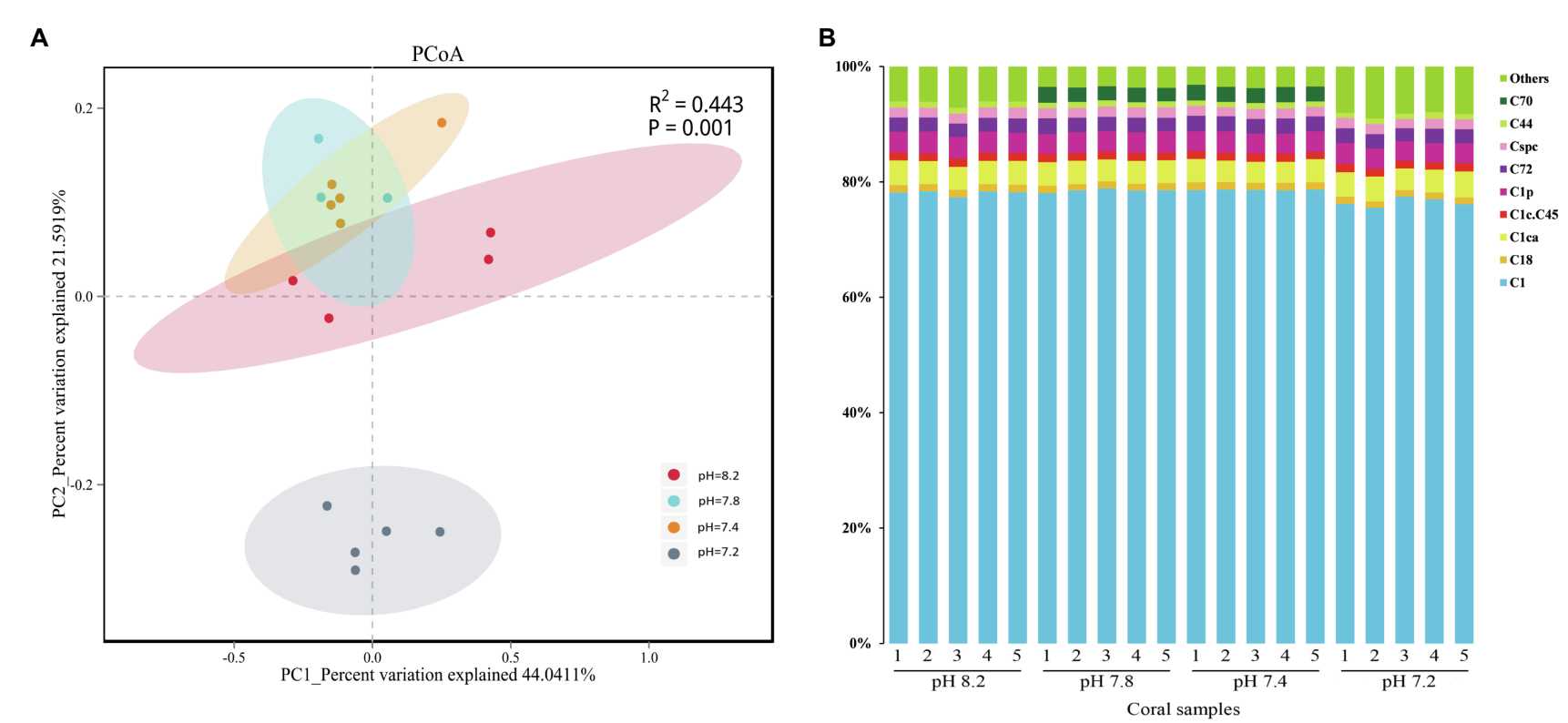

FIGURE 3 | Similarity of community structure and relative abundance of Symbiodiniaceae. (A) Principal coordinates analysis (PCoA) on operational taxonomic unit (OTU) level. (B) Relative abundance of different Symbiodiniaceae subclades in coral samples.

A

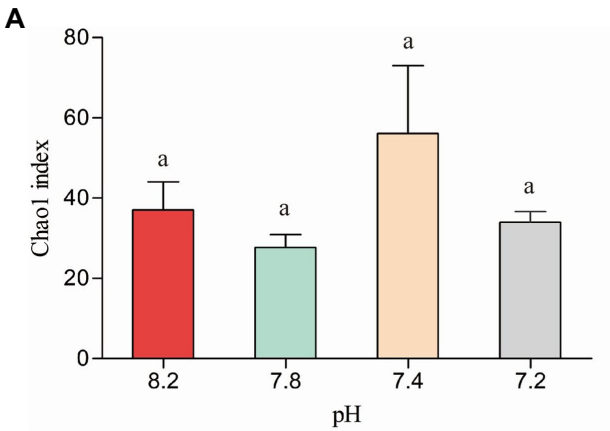

B

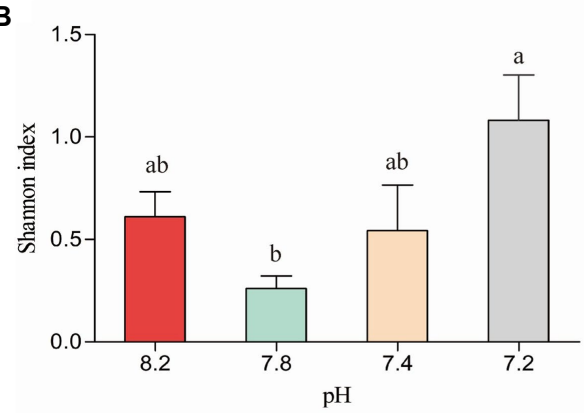

C

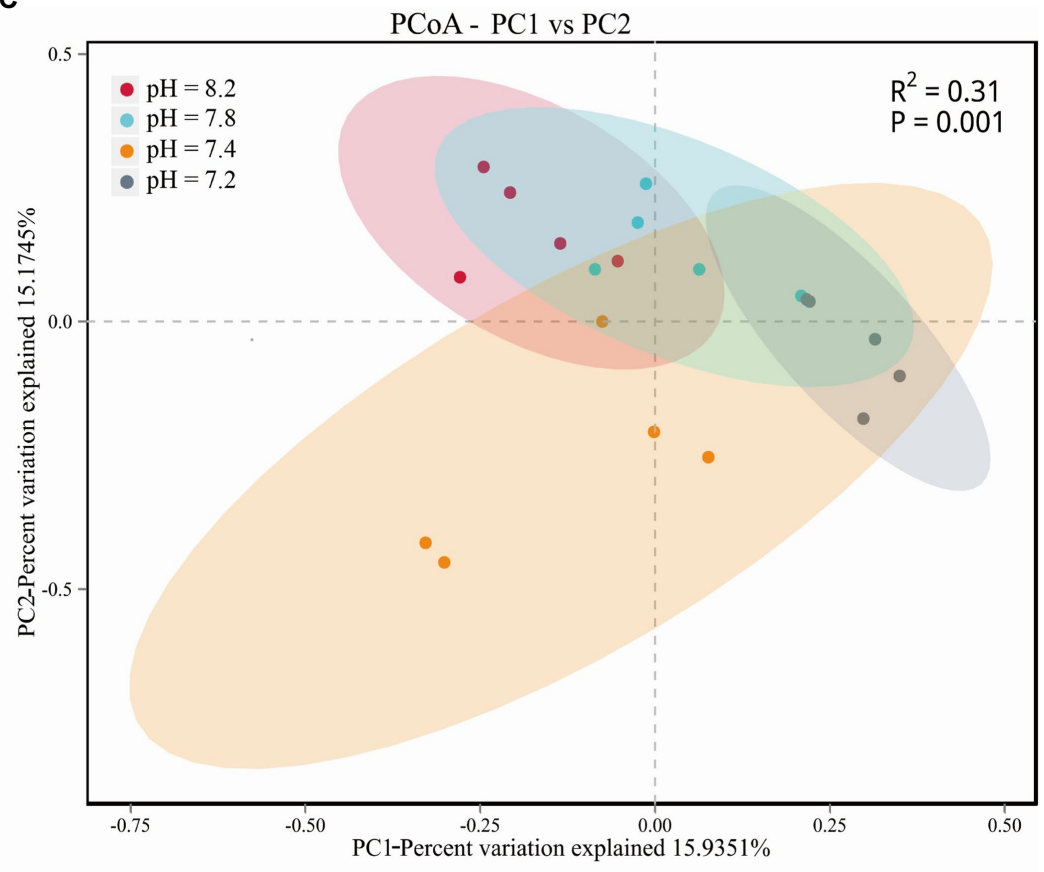

FIGURE 4 | (A) Chao1 diversity and (B) Shannon diversity indices values of Acropora valida-associated bacteria between different pH. The error bars are the mean \pm SD. values (C) PCoA of the unweighted UniFrac distance matrix representing differences in community composition at the OTU level. Lower case letters $(\mathrm{a}, \mathrm{b}, \mathrm{c})$ denote significant differences by Duncan post hoc test.

is, the difference between samples in this group was the largest. The two groups of $\mathrm{pH} 8.2$ and 7.8 had the highest similarity regarding the composition of the coral-associated bacterial community. The differences in the coral-associated bacteria between the two groups of $\mathrm{pH} 8.2$ and 7.2 were the largest, and the community composition changes between the groups 
were also the largest. Overall, the differences in the community composition of the coral-associated bacteria were significant under the different $\mathrm{pH}$ gradients (PERMANOVA, $p=0.001$ ).

Figure 5A shows that the most abundant commensal bacterial phyla in A. valida mainly included Proteobacteria, Firmicutes, Cyanobacteria, Bacteroidetes, Deinococcus-Thermus, Planctomycetes, and Actinobacteria. During the entire acidification process, the commensal bacteria took Proteobacteria as the first dominant bacteria phyla. When the seawater $\mathrm{pH}$ was $8.2,7.8$, and 7.4 , the relative abundance of Proteobacteria was $94.52,98.77$, and $97.91 \%$, respectively. When the seawater $\mathrm{pH}$ dropped to 7.2 , the average relative abundance of Proteobacteria dropped to $87.12 \%$ (Kruskal-Wallis: $H=13.057$, $p=0.005$, post hoc: Duncan). The relative abundance of Firmicutes at $\mathrm{pH} 8.2$ was $4.51 \% \pm 0.64 \%$. However, when acidified to $\mathrm{pH}$ 7.8 , the relative abundance of Firmicutes dropped rapidly and significantly below $1 \%$ (Kruskal-Wallis: $H=13.057, p=0.005$, post hoc: Duncan). It is worth noting that the relative abundance of Cyanobacteria significantly increased to $8.11 \pm 0.23 \%$ at $\mathrm{pH}$ 7.2 (Kruskal-Wallis: $H=10.726, p=0.013$, post hoc: Duncan). Figure 5B shows the main components included Endozoicomonadaceae (Proteobacteria; Gammaproteobacteria; Oceanospirillales), Paenibacillaceae (Firmicutes; Bacilli; Caryophanales), Cyclobacteriaceae (Bacteroidetes; Proteophagia;
Cytophagalobacteria), and Rhodobacteraceae (Proteobacteria; Alphaproteobacteria; Rhodobacterales) at the family level. At the genus level (Figure 5C), the community composition changes were consistent with that at the phylum level. Endozoicomonas (Proteobacteria; Endozoicomonadaceae) was the first dominant genus, wherein the relative abundance was between 58.70 and $99.31 \%$. When the $\mathrm{pH}$ of the surrounding seawater dropped to 7.2 , the relative abundance of Endozoicomonas decreased significantly (Kruskal-Wallis: $H=11.354, p=0.010$, post hoc: Duncan). Before the $\mathrm{pH}$ value of the surrounding seawater decreased ( $\mathrm{pH}$ 8.2), Paenibacillus (Firmicutes; Bacillales) was the second most dominant genus, with a relative abundance of $4.48 \pm 0.64 \%$. After acidification stress, the relative abundance of Paenibacillus dropped significantly to $1 \%$ or less (KruskalWallis: $H=14.885, p=0.002$, post hoc: Duncan). In addition, when the $\mathrm{pH}$ of the surrounding seawater dropped to 7.2 , the proportion of unclassified bacteria increased significantly (Kruskal-Wallis: $H=8.646, p=0.034$, post hoc: Duncan), and the relative abundance proportion was $8.74 \pm 1.93 \%$. In general, compared with the two high $\mathrm{pH}$ groups ( $\mathrm{pH} 8.2$ and 7.8), when the surrounding seawater was acidified to a lower value ( $\mathrm{pH} 7.4$ and 7.2), the abundance of coral-associated bacteria increased significantly at the genus level. As shown in Figure 5D, the relative abundance of Spongiobacter_nickelotoleran
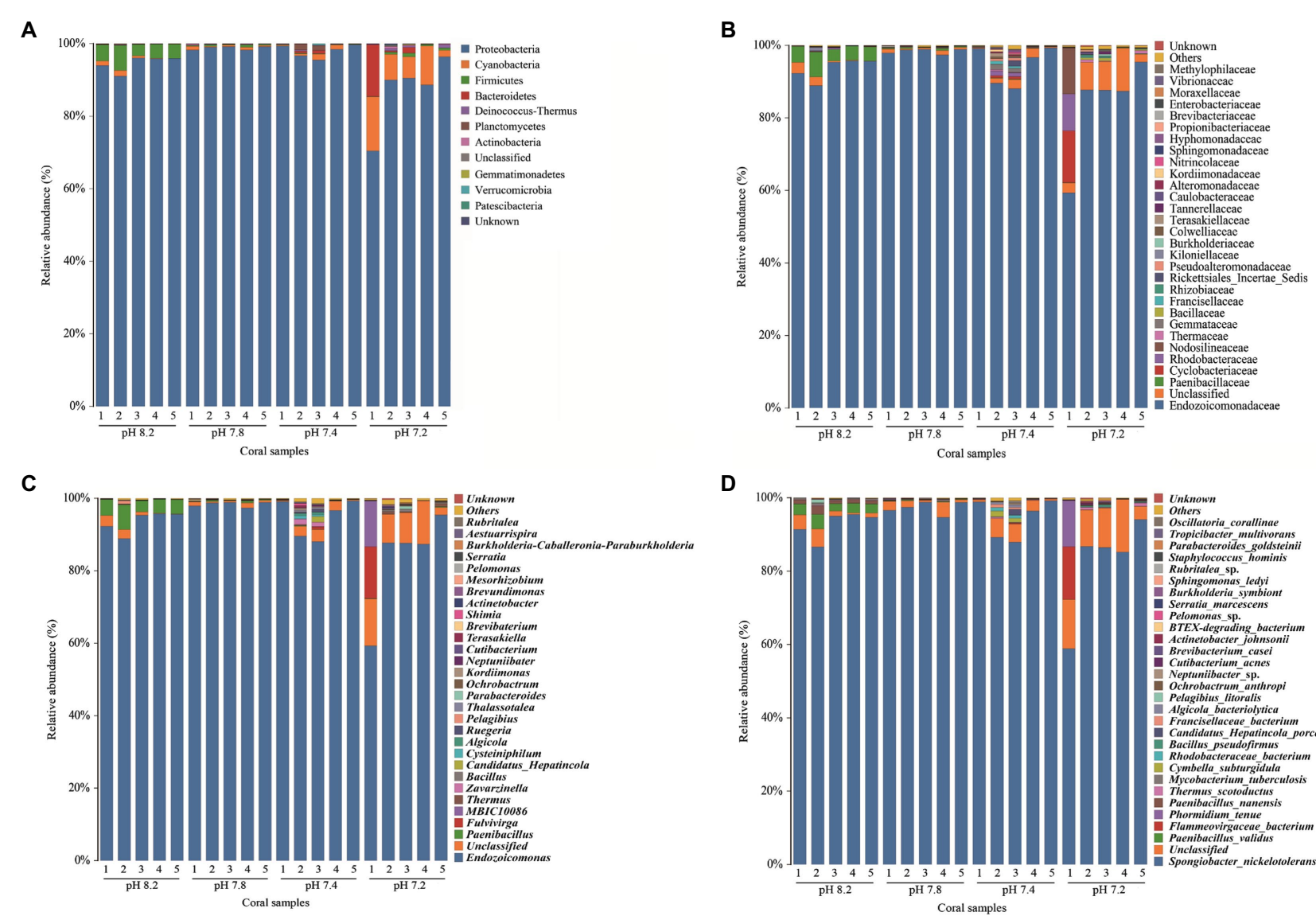

D

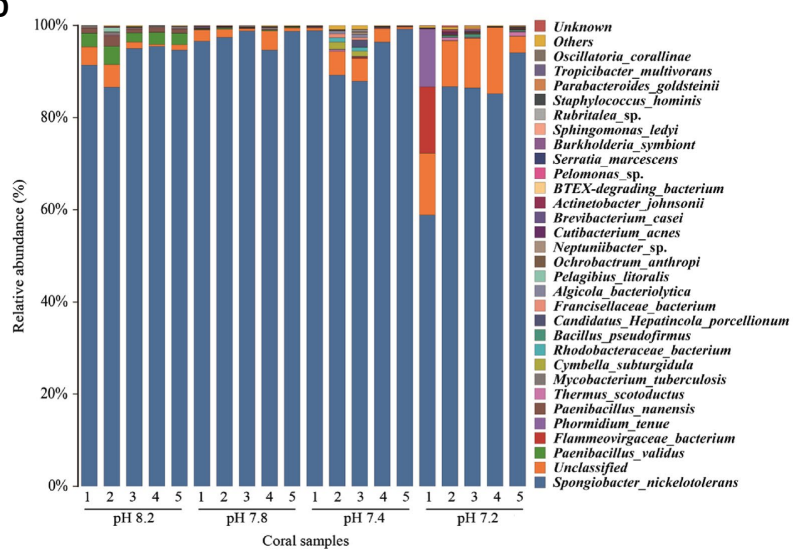

FIGURE 5 | Relative abundance of bacteria at different taxonomic levels in each pH group. (A) phylum, (B) family, (C) genus, and (D) species level. 
(Proteobacteria; Oceanospirillales; Endozoicomonas) was the highest at the species level, fluctuating between 58.42 and $99.29 \%$. When the $\mathrm{pH}$ of the surrounding seawater dropped to $\mathrm{pH} \mathrm{7.2,} \mathrm{the} \mathrm{mean} \mathrm{relative} \mathrm{abundance} \mathrm{of} \mathrm{Spongiobacter}$ nickelotoleran was significant, dropping to $82.18 \pm 6.1 \%$ (KruskalWallis: $H=4.92, p=0.178$, post hoc: Duncan). Before the $\mathrm{pH}$ value of the surrounding seawater was lowered ( $\mathrm{pH} 8.2$ ), Paenibacillus_validus (Firmicutes; Bacillales; Paenibacillus) was the second most dominant species, with a relative abundance of $2.77 \pm 0.32 \%$. After the implementation of acidification, the relative abundance of Paenibacillus_validus dropped significantly to $1 \%$ or less (Kruskal-Wallis: $H=13.959, p=0.003$, post hoc: Duncan). In addition, when the $\mathrm{pH}$ of the surrounding seawater dropped to 7.2, the proportion of unclassified species increased significantly (Kruskal-Wallis: $H=8.189, p=0.042$, post hoc: Duncan), and the total relative abundance proportion was $10.43 \pm 1.90 \%$.

Linear discriminant analysis effect size was used to analyze the significant differences between groups of bacterial communities from phylum to species (Figure 6). Fourteen taxa showed significant differences. Biomarkers with a $\mathrm{pH} 8.2$ gradient belonged to Firmicutes, which were Firmicutes at the phylum level, Bacilli at the class level, and Bacillales at the mesh level. Paenibacillaceae at the family level, Paenibacillus at the genus level, and Paenibacillus_validus at the species level. Proteobacteria (Gammaproteobacteria, Oceanospirillales, Endozoicomonadaceae, Endozoicomonas, and Spongiobacter_nickelotoleran) under $\mathrm{pH}$ 7.8 showed significant differences from other $\mathrm{pH}$ groups; no significant biomarkers were found at the $\mathrm{pH} 7.4$ gradient; and when the $\mathrm{pH}$ dropped to 7.2 , the phylum level Cyanobacteria and Oxyphotobacteria at the class level become significant biomarkers under the acidification conditions.

\section{DISCUSSION}

\section{Acropora valida Shows Strong Adaptability to Ocean Acidification}

During the acidification simulation experiment, when the $\mathrm{pH}$ value of the surrounding seawater continued to decrease, $A$. valida did not experience apparent bleaching, and the coral tentacles were still able to stretch freely (Figure 1). The results showed that the Symbiodiniaceae density decreased significantly under ocean acidification (Figure 2A). When the $\mathrm{pH}$ dropped to 7.8 or below, the Symbiodiniaceae density decreased significantly. When the $\mathrm{pH}$ reached 7.2 , the Symbiodiniaceae density was $0.22 \pm 0.16 \times 10^{6} \mathrm{cells} \cdot \mathrm{cm}^{-2}$, which was about $19 \%$ of the density at $\mathrm{pH}$ 8.2. It is noteworthy that, despite the continuous decrease of Symbiodiniaceae density under ocean acidification, the real-time photosynthetic efficiency of $A$. valida did not change significantly and remained at about $0.62 \mu \mathrm{mol} \cdot \mathrm{m}^{2} \cdot \mathrm{s}^{-1}$ (Figure 2B).

Although there have been previous reports on coral bleaching caused by acidification (Anlauf et al., 2011), more and more pieces of evidence show that many corals have strong adaptability to acidification (Schneider and Erez, 2006; Anlauf et al., 2011;

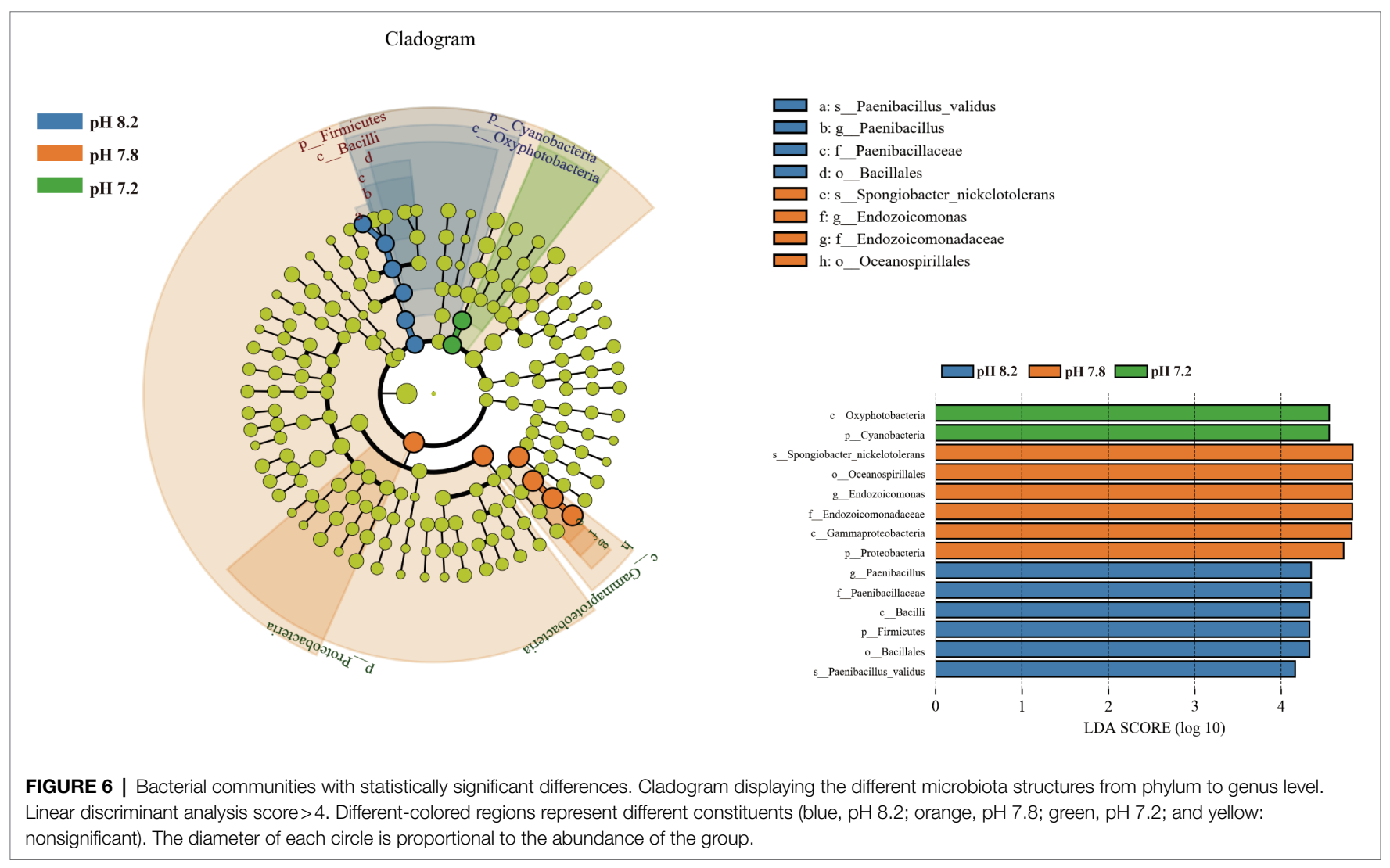


Baghdasarian et al., 2017; Krueger et al., 2017; Meunier et al., 2021; Zhou et al., 2021). For example, Noonan and Fabricius (2015) studied the response of Seriatopora hystrix and Acropora millepora to ocean acidification, finding that elevated $\mathrm{CO}_{2}$ partial pressure ( $\mathrm{pH}$ 7.79) had no adverse effects on both coral (Noonan and Fabricius, 2015). Moreover, Wall et al. (2014) found that elevated $\mathrm{CO}_{2}$ concentration did not affect the photosynthetic physiological parameters and productivity of Seriatopora caliendrum holobiont nor did it cause coral bleaching (Wall et al., 2014), whereas Krueger et al. (2017) found that Stylophora pistillata on Aqaba Island did not show bleaching after 1.5 months under high temperature and acidification ( $\mathrm{pH}$ 7.8; Krueger et al., 2017). Furthermore, Rodolfo-Metalpa et al. (2010) found that acidification $\left(\mathrm{pCO}_{2}=700 \mu \mathrm{atm}\right)$ did not affect the photosynthetic efficiency and calcification rate of Cladocora caespitosa nor did it cause coral bleaching (Rodolfo-Metalpa et al., 2010).

The Symbiodiniaceae density is an essential indicator of coral health (Jones and Yellowlees, 1997; Baker et al., 2008; Qin et al., 2019). Studies indicate that Symbiodiniaceae density would decrease with ocean acidification (Kaniewska et al., 2012; Mason, 2018). For example, Krief et al. (2010) found that the Symbiodiniaceae densities of Porites sp. and S. pistillata at $\mathrm{pH}$ 7.49 and 7.19 were significantly lower than that at $\mathrm{pH} 8.09$ (Krief et al., 2010). Kaniewska et al. (2012) found that A. millepora lost more than $50 \%$ of the Symbiodiniaceae under high $\mathrm{CO}_{2}$ partial pressure (Kaniewska et al., 2012). However, it is noteworthy that the decrease in Symbiodiniaceae density does not necessarily cause coral bleaching or even death. Studies have shown that even healthy corals of the same species in the same sea area will show significant differences in the density of Symbiodiniaceae due to the alternation of the seasons; that is, there is no bleaching in the summer and autumn when the density of Symbiodiniaceae is at its lowest (Shenkar et al., 2006; Li et al., 2008; Xu et al., 2017). Li et al. (2008) studied the effects of high temperature on Pocillopora damicornis in the Hainan Island and found that $32^{\circ} \mathrm{C}$ high-temperature stress caused the loss of $43.5 \%$ of the Symbiodiniaceae in the $P$. damicornis, but this did not lead to coral bleaching (Shu et al., 2008). Moreover, studies on the density of Symbiodiniaceae in corals in the southern South China Sea also showed that even though the density of Symbiodiniaceae in corals was $31-53 \%$ lower than that in the other areas, the corals still survived and maintained good coverage without bleaching (Li et al., 2011).

The photosynthetic efficiency of coral symbiotic algae can also indicate coral health (Smith et al., 2005; Xu et al., 2017). Research by Mason (2018) showed that the Galaxea fascicularis excreted $71 \%$ of the Symbiodiniaceae under acidification. However, the remaining Symbiodiniaceae increased their photosynthetic pigments to maintain the energy supply through photosynthesis (Mason, 2018). Schneider and Erez (2006) reported that $A$. eurystoma photosynthetic efficiency did not change significantly under pH 7.9-8.5 (Schneider and Erez, 2006). Furthermore, Zheng et al. (2015) believed that ocean acidification ( $\mathrm{pH} 7.8$ ) had no significant effect on the maximum photosynthetic efficiency of $P$. damicornis (Zheng et al., 2015), and Wall et al. (2014) believed that the effect of acidification on the photosynthetic efficiency of S. caliendrum is negligible (Wall et al., 2014). Some studies even show that acidification is beneficial to the photosynthesis of coral symbiotic algae (Pearse and Muscatine, 1971; Crawley et al., 2010). For example, Uthicke and Fabricius (2012) found that with the increase of carbon content in seawater ( $\mathrm{pH}$ 7.8), the primary photosynthetic productivity of Marginopora vertebralis symbiotic algae increased by $90 \%$ (Uthicke and Fabricius, 2012). Biscéré et al. (2019) found that rates of photosynthesis by Symbiodiniaceae were higher at the high $\mathrm{CO}_{2}$ site compared to the ambient site in Papua New Guinea (Biscéré et al., 2019).

In this study, although acidification reduced the Symbiodiniaceae density of $A$. valida by about $80 \%$, acidification had almost no noticeable effect on its photosynthetic efficiency, and the coral tentacles were still able to stretch freely. Taken together, this study demonstrated that $A$. valida is very adaptable to ocean acidification.

\section{The Community Composition of the Coral- Symbiodiniaceae Symbiosis System Is Hardly Affected by Acidification}

The composition of the dominant types of Symbiodiniaceae of A. valida did not change significantly during the entire acidification process, and the $\mathrm{C} 1$ subclade always occupied an absolute advantage, with a stable symbiosis with $A$. valida during the entire acidification process (Figure 3B). However, at $\mathrm{pH}$ 7.2 , the relative abundance of the Symbiodiniaceae background types (Figure 3B, Others) increased significantly to $8.27 \%$.

Several studies currently suggest that ocean acidification has no significant impact on the dominant types of Symbiodiniaceae (Noonan et al., 2013; Davies et al., 2018). For example, Zhou et al. (2017) studied the Symbiodiaceae community of A. gemmifera under different $\mathrm{pH}$ conditions $(\mathrm{pH} 8.1,7.8$, and 7.5) and found that it was always dominated by the D17 group (Zhou et al., 2017). Davies et al. (2018) also found that acidification $\left(\mathrm{pCO}_{2}=2,553 \mu \mathrm{atm}\right)$ had no significant effect on the dominant types of Symbiodiniaceae (C1 subclade) in Siderastrea sidereal (Davies et al., 2018). Moreover, the Symbiodiniaceae composition of six coral species in the $\mathrm{CO}_{2}$ crater ( $\mathrm{pH}$ 7.8-7.9) of PNG and of the same corals far away from the crater ( $\mathrm{pH} 8.0-8.05)$ were found to have no difference (Noonan et al., 2013). The above results are consistent with the experimental results of the present study. The C1 subclade had high photosynthetic efficiency and tolerance to low temperature and nitrogen-rich environments (Baker et al., 2013; Ng and Ang, 2016; Morgans et al., 2020). Previously, the D clade Symbiodiniaceae were considered to have stronger high-temperature resistance (Berkelmans and van Oppen, 2006; LaJeunesse et al., 2014). However, the latest research shows that Cladocopium goreaui (C1) and Durusdinium trenchii (D1a) are used as probiotics and have been inoculated into A. millepora and subjected to heat stress. Corals with $C$. goreaui $(\mathrm{C} 1)$ showed less bleaching and had an increased photosynthetic efficiency (Morgans et al., 2020). Cantin et al. (2009) found that in A. millepora Symbiodiniaceae, the relative electron transport of the $\mathrm{C} 1$ subclade through photosystem II was $87 \%$ higher than that of the $\mathrm{D}$ clade (Cantin et al., 2009). Given that the C1 subclade is a type of Symbiodiniaceae with high photosynthetic capacity, it is 
reasonable to speculate that the dominant advantage of the $\mathrm{C} 1$ subclade in A. valida may explain the stability of photosynthetic efficiency in the acidification experiment and compensate for the adverse effects of acidification on the Symbiodiniaceae density.

The Symbiodiniaceae background types serve as the basis for the plasticity of Symbiodiniaceae communities (Shade et al., 2014), which stability is affected by environmental changes (Quigley et al., 2014). Ziegler et al. (2018) reported that the change in the dominant types could not explain the range of coral response to pressure because the dominant types share the coral reef ecosystem in a broad environmental gradient, and the members of the Symbiodiniaceae background types are likely to be the same as the members of the rare bacterial biosphere, which are more active than the members of the dominant group; therefore, different members of the background types may be an essential part of supporting corals in response to environmental changes (Ziegler et al., 2018). When environmental stress induces reorganization or conversion of Symbiodiniaceae, the interaction between members of the Symbiodiniaceae background types may be more prominent (Boulotte et al., 2016). A theoretical network modeling on the relationship between corals and Symbiodiniaceae under climate change predicts that the increase in Symbiodiniaceae diversity and the decrease in Symbiodiniaceae types often occur at low abundance (Fabina et al., 2013). They provide redundancy or complementary symbiotic functions that can significantly improve the stability of the response of the community to environmental changes. Therefore, although the Symbiodiniaceae background types in this acidification experiment did not account for a high proportion, the significant increase in the relative abundance of the Symbiodiniaceae background types at $\mathrm{pH} 7.2$ indicates that $A$. valida is likely to improve the stability of the Symbiodiniaceae community to acidification by increasing the abundance of the Symbiodiniaceae background types.

In summary, this short term of ocean acidification did not have a significant impact on the composition of the Symbiodiniaceae dominant types in $A$. valida. The stable symbiosis of the $\mathrm{C} 1$ subclade with high photosynthetic capacity and A. valida probably compensated for the adverse effect of acidification on the Symbiodiniaceae density, maintaining the stability of photosynthetic efficiency. The significant increase in the relative abundance of the A. valida Symbiodiniaceae background types is likely to enhance the stability of the Symbiodiniaceae community and help corals adapt to the acidic environment. However, the changes of the Symbiodiniaceae community composition in A. valida under long-term acidification stress are worthy of further study.

\section{Changes in the Composition of the Coral- Associated Bacteria Help Corals Adapt to an Acidified Environment}

Using the $16 \mathrm{~S}$ rRNA clone library to identify and analyze the microbial community of A. valida, four major bacterial phyla were identified - Proteobacteria, Firmicutes, Cyanobacteria, and Bacteroidetes (Figure 5A) - that agree with previous findings (Bourne and Munn, 2005; Sekar et al., 2006; Wegley et al., 2007). At the genus level, the coral probiotic Endozoicomonas always dominated (Figure 5C). In addition, at $\mathrm{pH}$ 7.8, the relative abundance of Firmicutes decreased significantly, whereas, at $\mathrm{pH} 7.2$, the relative abundance of Cyanobacteria increased significantly (Figure 5A).

Endozoicomonas (Gammaproteobacteria) is a bacterium that exists widely in coral reefs globally (Neave et al., 2016) because it accounts for a relatively high proportion of healthy corals (Vezzulli et al., 2013; O'Brien et al., 2016; Shiu et al., 2017) and is thus considered as a potential indicator of coral health (Bourne et al., 2008). Studies based on catalytic messenger deposition-fluorescence in situ hybridization (CARD-FISH) have proved that Endozoicomonas symbiotically exists in the endoderm tissue of corals and are closely related to corals (Bayer et al., 2013; Neave et al., 2017). Endozoicomonas belongs to Family Hahellaceae and Order Oceanospirillales and is a group of heterotrophic, aerobic marine bacteria that can decompose various organic compounds (Garrity, 2007). Studies have shown that the main function of Endozoicomonas is to participate in the sulfur cycle of the coral holobiont by metabolizing dimethylsulfoniopropionate (DMSP; Raina et al., 2009, 2010). It provides beneficial protection for the Symbiodiniaceae in the holobiont from albino pathogens (Morrow et al., 2012; Pantos et al., 2015), participates in the transport of protein and carbohydrates (La Riviere et al., 2013), and provides advantages for coral health by producing antibacterial compounds (Bourne et al., 2008). Therefore, the absolute advantage of Endozoicomonas is likely to help A. valida adapt to ocean acidification.

The adaptation of $A$. valida to ocean acidification may also be closely related to changes in the composition of the coralassociated bacterial community. Meron et al. (2011) found that the relative abundances of Firmicutes, Bacteroidetes, and Cyanobacteria in A. millepora increased under acidification $(\mathrm{pH}$ 7.3). In addition, the relative abundances of Vibrio sp. and Alteromonas sp. related to diseases in A. millepora were increased. It also increased significantly (Meron et al., 2011). Some studies suggest that Bacteroidetes are related to the Black Band Disease and that Firmicutes and Bacteroidetes come from the same diseased tissue (Cooney et al., 2002; Frias-Lopez et al., 2002, 2004). Therefore, the increase in Firmicutes and Bacteroidetes may be a manifestation of the threat of acidification to coral health (Meron et al., 2011). The present experiments did not find an increase in disease-related Bacteroidetes, Firmicutes, Vibrio sp., and Alteromonas sp., and the relative abundance of Firmicutes also decreased significantly at $\mathrm{pH} 7.8$, indicating that $A$. valida was in a healthy state throughout the acidification experiment. Being in a healthy state during coercion is also consistent with the appearance of $A$. valida without bleaching or disease. As important photosynthetic microorganisms in seawater, Cyanobacteria are closely related to the nitrogen fixation that depends on photosynthesis in coral reefs (Lesser et al., 2004). The increase in Cyanobacteria contributes to the increase in carbon fixation capacity (Zhang et al., 2018). Studies have shown that some reef sponges can increase the relative abundance of Cyanobacteria to make them more competitive than corals under ocean acidification (Bell et al., 2013; Morrow et al., 2015). Therefore, the increase in Cyanobacteria under acidification stress ( $\mathrm{pH} 7.2$ ) may be a response of $A$. valida to the composition of bacterial communities to adapt to acidification stress. The increase in Cyanobacteria is likely to 
provide compensation for the photosynthesis of coral holobiont, ensuring the energy supply that is needed by corals in low pH environments. A new study by Meunier et al. (2021) found that at the $\mathrm{CO}_{2}$ seeps of Tutum Bay (PNG), P. damicornis modified its $\mathrm{N}$ assimilation pathways by utilizing picoplanktonsized unicellular Cyanobacteria (Synechococcus sp.) in oligotrophic waters to offset the increasing $\mathrm{N}$ requirements under high $\mathrm{CO}_{2}$ (Meunier et al., 2021). This is consistent with our research results.

In summary, the stable symbiosis of Endozoicomonas and A. valida under acidification stress may help it adapt to the acidified environment. The increase in the relative abundance of Cyanobacteria and other photosynthetic bacteria at $\mathrm{pH} 7.2$ is likely to contribute to the photosynthesis of coral symbionts and ensure the energy supply for coral survival in a low $\mathrm{pH}$ environment. Therefore, the stability and flexibility of the coral-associated bacterial community help A. valida to withstand acidification stress.

\section{CONCLUSION}

In this study, an indoor simulation of ocean acidification was conducted. Changes in the composition of the Symbiodiniaceae and coral-associated bacterial communities of reef-building corals under different $\mathrm{pH}$ degrees occurred. Hence, the response of A. valida to ocean acidification is likely a complex biological process, which includes the dynamic changes in the coral hosts, coral-associated bacteria, and Symbiodiniaceae. This study suggests that, although ocean acidification caused a significant decrease in the density of Symbiodiniaceae, A. valida did not show significant bleaching, with the real-time photosynthetic efficiency of the holobiont remained unchanged and the coral tentacles were still able to stretch freely, which well-adapted to the acidification stress. Thus, the Symbiodiniaceae and bacteria of the coral holobiont were involved in corals adapting to acidification stress. Regarding the Symbiodiniaceae, the stable symbiosis between the $\mathrm{C} 1$ subclade, with the high photosynthetic ability, and A. valida in the dominant system group probably compensated for the negative impact of acidification on the density of Symbiodiniaceae, explaining why the photosynthetic efficiency remained stable. In addition, the increase in the relative abundance of the Symbiodiniaceae background types could enhance the stability of the Symbiodiniaceae community composition. In terms of the coral-associated bacteria, the stable symbiosis of Endozoicomonas and A. valida under acidification stress could help A. valida to adapt to the acidification environment, and

\section{REFERENCES}

Albright, R., and Langdon, C. (2011). Ocean acidification impacts multiple early life history processes of the Caribbean coral Porites astreoides. Glob. Chang. Biol. 17, 2478-2487. doi: 10.1111/j.1365-2486.2011.02404.x

Anlauf, H., D'Croz, L., and O'Dea, A. (2011). A corrosive concoction: The combined effects of ocean warming and acidification on the early growth of a stony coral are multiplicative. J. Exp. Mar. Biol. Ecol. 397, 13-20. doi: 10.1016/j.jembe.2010.11.009

Arif, C., Daniels, C., Bayer, T., Banguera-Hinestroza, E., Barbrook, A., Howe, C. J., et al. (2014). Assessing Symbiodinium diversity in scleractinian corals via the significant increase in the relative abundance of Cyanobacteria at $\mathrm{pH} 7.2$ could provide compensation for the photosynthetic efficiency of the coral symbiosis. In summary, the stability and flexibility of the Symbiodiniaceae community and the coralassociated bacterial community together helped $A$. valida resist the threats of ocean acidification, which also indicates that corals can adapt to ocean acidification by adjusting their holobiont.

\section{DATA AVAILABILITY STATEMENT}

The data presented in the study are deposited in the NCBI SRA repository. The accession numbers are PRJNA761014 for the sequence of Acropora valida-associated bacteria and PRJNA761031 for the sequence Acropora valida symbiotic Symbiodiniaceae respectively.

\section{AUTHOR CONTRIBUTIONS}

RG: conceptualization, methodology, formal analysis, investigation, resources, project administration, data curation, writing - original draft, writing - review and editing, visualization, software, and project administration. JL: conceptualization, methodology, validation, writing - review and editing, and supervision. KY: conceptualization, writing - review and editing, supervision, and funding acquisition. BC: software and writing review and editing. XY: writing - review and editing. $\mathrm{CD}$, JC, YX, and LQ: resources. All authors contributed to the article and approved the submitted version.

\section{FUNDING}

This work was supported by the National Natural Science Foundation of China (Nos. 42030502 and 42090041), the Guangxi scientific projects (No. AD17129063 and AA17204074), the BaGui Scholars Program Foundation (No. 2014BGXZGX03), and the Natural Sciences Foundation of Guangxi (2018GXNSFAA281328).

\section{ACKNOWLEDGMENTS}

We are grateful to all the laboratory members for their continuous technical advice and helpful discussions.

next-generation sequencing-based genotyping of the ITS2 rDNA region. Mol. Ecol. 23, 4418-4433. doi: 10.1111/mec.12869

Baghdasarian, G., Osberg, A., Mihora, D., Putnam, H., Gates, R. D., and Edmunds, P. J. (2017). Effects of temperature and $\mathrm{pCO}_{2}$ on population regulation of Symbiodinium spp. in a tropical reef coral. Biol. Bull. 232, 123-139. doi: $10.1086 / 692718$

Baker, D. M., Andras, J. P., Jordan-Garza, A. G., and Fogel, M. L. (2013). Nitrate competition in a coral symbiosis varies with temperature among Symbiodinium clades. ISME J. 7, 1248-1251. doi: 10.1038/ismej.2013.12

Baker, A. C., Glynn, P. W., and Riegl, B. (2008). Climate change and coral reef bleaching: An ecological assessment of long-term impacts, recovery 
trends and future outlook. Estuar. Coast. Shelf Sci. 80, 435-471. doi: 10.1016/j. ecss.2008.09.003

Bayer, T., Neave, M. J., Alsheikh-Hussain, A., Aranda, M., Yum, L. K., Mincer, T., et al. (2013). The microbiome of the red sea coral Stylophora pistillata is dominated by tissue-associated Endozoicomonas bacteria. Appl. Environ. Microbiol. 79, 4759-4762. doi: 10.1128/aem.00695-13

Bell, J. J., Davy, S. K., Jones, T., Taylor, M. W., and Webster, N. S. (2013). Could some coral reefs become sponge reefs as our climate changes? Glob. Chang. Biol. 19, 2613-2624. doi: 10.1111/gcb.12212

Ben-Haim, Y., Zicherman-Keren, M., and Rosenberg, E. (2003). Temperatureregulated bleaching and lysis of the coral Pocillopora damicornis by the novel pathogen vibrio coralliilyticus. Appl. Environ. Microbiol. 69, 4236-4242. doi: $10.1128 /$ aem.69.7.4236-4242.2003

Berkelmans, R., and van Oppen, M. J. H. (2006). The role of zooxanthellae in the thermal tolerance of corals: a 'nugget of hope' for coral reefs in an era of climate change. Proc. R. Soc. Lond. B Biol. Sci. 273, 2305-2312. doi: 10.1098/rspb.2006.3567

Biscéré, T., Zampighi, M., Lorrain, A., Jurriaans, S., Foggo, A., Houlbrèque, F., et al. (2019). High $\mathrm{pCO}_{2}$ promotes coral primary production. Biol. Lett. 15:20180777. doi: $10.1098 /$ rsbl.2018.0777

Bolger, A. M., Lohse, M., and Usadel, B. (2014). Trimmomatic: A flexible trimmer for Illumina sequence data. Bioinformatics 30, 2114-2120. doi: 10.1093/bioinformatics/btu170

Boulotte, N. M., Dalton, S. J., Carroll, A. G., Harrison, P. L., Putnam, H. M., Peplow, L. M., et al. (2016). Exploring the Symbiodinium rare biosphere provides evidence for symbiont switching in reef-building corals. ISME J. 10, 2693-2701. doi: 10.1038/ismej.2016.54

Bourne, D., Iida, Y., Uthicke, S., and Smith-Keune, C. (2008). Changes in coral-associated microbial communities during a bleaching event. ISME J. 2, 350-363. doi: 10.1038/ismej.2007.112

Bourne, D. G., Morrow, K. M., and Webster, N. S. (2016). Insights into the coral microbiome: underpinning the health and resilience of reef ecosystems. Annu. Rev. Microbiol. 70, 317-340. doi: 10.1146/annurev-micro-102215-095440

Bourne, D. G., and Munn, C. B. (2005). Diversity of bacteria associated with the coral Pocillopora damicornis from the great barrier reef. Environ. Microbiol. 7, 1162-1174. doi: 10.1111/j.1462-2920.2005.00793.x

Cantin, N. E., van Oppen, M. J. H., Willis, B. L., Mieog, J. C., and Negri, A. P. (2009). Juvenile corals can acquire more carbon from high-performance algal symbionts. Coral Reefs 28, 405-414. doi: 10.1007/s00338-009-0478-8

Chen, B., Yu, K., Liang, J., Huang, W., Wang, G., Su, H., et al. (2019). Latitudinal variation in the molecular diversity and community composition of Symbiodiniaceae in coral from the South China Sea. Front. Microbiol. 10:1278. doi: $10.3389 /$ fmicb.2019.01278

Chen, B., Yu, K., Liao, Z., Yu, X., Qin, Z., Liang, J., et al. (2020). Microbiome community and complexity indicate environmental gradient acclimatisation and potential microbial interaction of endemic coral holobionts in the South China Sea. Sci. Total Environ. 765:142690. doi: 10.1016/j.scitotenv.2020.142690

Comeau, S., Carpenter, R. C., and Edmunds, P. J. (2017). Effects of $\mathrm{pCO}_{2}$ on photosynthesis and respiration of tropical scleractinian corals and calcified algae. ICES J. Mar. Sci. 74, 1092-1102. doi: 10.1093/icesjms/fsv267

Cooney, R. P., Pantos, O., Le Tissier, M. D. A., Barer, M. R., O'Donnell, A. G., and Bythell, J. C. (2002). Characterization of the bacterial consortium associated with black band disease in coral using molecular microbiological techniques. Environ. Microbiol. 4, 401-413. doi: 10.1046/j.1462-2920.2002.00308.x

Crawley, A., Kline, D. I., Dunn, S., Anthony, K. R. N., and Dove, S. (2010). The effect of ocean acidification on symbiont photorespiration and productivity in Acropora formosa. Glob. Chang. Biol. 16, 851-863. doi: 10.1111/j.1365-2486.2009.01943.x

Davies, S. W., Ries, J. B., Marchetti, A., and Castillo, K. D. (2018). Symbiodinium functional diversity in the coral Siderastrea siderea is influenced by thermal stress and reef environment, but not ocean acidification. Front. Mar. Sci. 5, 150. doi: 10.3389/fmars.2018.00150

Fabina, N. S., Putnam, H. M., Franklin, E., Stat, M., and Gates, R. D. (2013). Symbiotic specificity, association patterns, and function determine community responses to global changes: defining critical research areas for coralSymbiodinium symbioses. Glob. Chang. Biol. 19, 3306-3316. doi: 10.1111/ gcb. 12320

Franklin, E. C., Stat, M., Pochon, X., Putnam, H. M., and Gates, R. D. (2012). GeoSymbio: A hybrid, cloud-based web application of global geospatial bioinformatics and ecoinformatics for Symbiodinium-host symbioses. Mol. Ecol. Resour. 12, 369-373. doi: 10.1111/j.1755-0998.2011.03081.x

Frias-Lopez, J., Klaus, J. S., Bonheyo, G. T., and Fouke, B. W. (2004). Bacterial community associated with black band disease in corals. Appl. Environ. Microbiol. 70, 5955-5962. doi: 10.1128/aem.70.10.5955-5962.2004

Frias-Lopez, J., Zerkle, A. L., Bonheyo, G. T., and Fouke, B. W. (2002). Partitioning of bacterial communities between seawater and healthy, black band diseased, and dead coral surfaces. Appl. Environ. Microbiol. 68, 2214-2228. doi: 10.1128/ aem.68.5.2214-2228.2002

Garrity, G. (2007). Bergey's Manual ${ }^{\circledR}$ of Systematic Bacteriology: Volume 2: The Proteobacteria, Part B: The Gammaproteobacteria (Vol. 2). Springer Science \& Business Media.

Goiran, C., AlMoghrabi, S., Allemand, D., and Jaubert, J. (1996). Inorganic carbon uptake for photosynthesis by the symbiotic coral/dinoflagellate association I. Photosynthetic performances of symbionts and dependence on sea water bicarbonate. J. Exp. Mar. Biol. Ecol. 199, 207-225. doi: 10.1016/0022-0981(95)00201-4

Hoegh-Guldberg, O., Mumby, P. J., Hooten, A. J., Steneck, R. S., Greenfield, P., Gomez, E., et al. (2007). Coral reefs under rapid climate change and ocean acidification. Science 318, 1737-1742. doi: 10.1126/science.1152509

Jones, R. J., and Yellowlees, D. (1997). Regulation and control of intracellular algae (equals zooxanthellae) in hard corals. Philos. Trans. R. Soc. Lond. B Biol. Sci. 352, 457-468. doi: 10.1098/rstb.1997.0033

Kaniewska, P., Campbell, P. R., Kline, D. I., Rodriguez-Lanetty, M., Miller, D. J., Dove, S., et al. (2012). Major cellular and physiological impacts of ocean acidification on a reef building coral. PLoS One 7:e34659. doi: 10.1371/ journal.pone.0034659

Kenkel, C. D., Moya, A., Strahl, J., Humphrey, C., and Bay, L. K. (2018). Functional genomic analysis of corals from natural $\mathrm{CO}_{2}$-seeps reveals core molecular responses involved in acclimatization to ocean acidification. Glob. Chang. Biol. 24, 158-171. doi: 10.1111/gcb.13833

Krief, S., Hendy, E. J., Fine, M., Yam, R., Meibom, A., Foster, G. L., et al. (2010). Physiological and isotopic responses of scleractinian corals to ocean acidification. Geochim. Cosmochim. Acta 74, 4988-5001. doi: 10.1016/j. gca.2010.05.023

Kroeker, K. J., Kordas, R. L., Crim, R. N., and Singh, G. G. (2010). Metaanalysis reveals negative yet variable effects of ocean acidification on marine organisms. Ecol. Lett. 13, 1419-1434. doi: 10.1111/j.1461-0248.2010.01518.x

Krueger, T., Horwitz, N., Bodin, J., Giovani, M. E., Escrig, S., Meibom, A., et al. (2017). Common reef-building coral in the northern Red Sea resistant to elevated temperature and acidification. R. Soc. Open Sci. 4:170083. doi: $10.1098 /$ rsos. 170038

Kuczynski, J., Stombaugh, J., Walters, W. A., González, A., Caporaso, J. G., and Knight, R. (2011). Using QIIME to analyze 16S rRNA gene sequences from microbial communities. Curr. Protoc. Bioinformatics 36:Unit 10.7. doi: 10.1002/0471250953.bi1007s36

La Riviere, M., Roumagnac, M., Garrabou, J., and Bally, M. (2013). Transient shifts in bacterial communities associated with the temperate Gorgonian Paramuricea clavata in the Northwestern Mediterranean Sea. PLoS One 8:e57385. doi: 10.1371/journal.pone.0057385

LaJeunesse, T. C., Parkinson, J. E., Gabrielson, P. W., Jeong, H. J., Reimer, J. D., Voolstra, C. R., et al. (2018). Systematic revision of Symbiodiniaceae highlights the antiquity and diversity of coral endosymbionts. Curr. Biol. 28, 2570-2580.e6. doi: 10.1016/j.cub.2018.07.008

LaJeunesse, T. C., Wham, D. C., Pettay, D. T., Parkinson, J. E., Keshavmurthy, S., and Chen, C. A. (2014). Ecologically differentiated stress-tolerant endosymbionts in the dinoflagellate genus Symbiodinium (Dinophyceae) clade D are different species. Phycologia 53, 305-319. doi: 10.2216/13-186.1

Leclercq, N., Gattuso, J. P., and Jauber, J. (2002). Primary production, respiration, and calcification of a coral reef mesocosm under increased $\mathrm{CO}_{2}$ partial pressure. Limnol. Oceanogr. 47, 558-564. doi: 10.4319/ lo.2002.47.2.0558

Lesser, M. P., Mazel, C. H., Gorbunov, M. Y., and Falkowski, P. G. (2004). Discovery of symbiotic nitrogen-fixing cyanobacteria in corals. Science 305, 997-1000. doi: 10.1126/science.1099128

Li, S., Yu, K., Chen, T., Shi, Q., and Zhang, H. L. (2011). Assessment of coral bleaching using symbiotic zooxanthellae density and satellite remote sensing data in the Nansha Islands, South China Sea. Chin. Sci. Bull. 56, 1031-1037. doi: $10.1007 / \mathrm{s} 11434-011-4390-6$ 
Li, S., Yu, K., Shi, Q., Chen, T. R., Zhao, M. X., and Zhao, J. X. (2008). Interspecies and spatial diversity in the symbiotic zooxanthellae density in corals from northern South China Sea and its relationship to coral reef bleaching. Chin. Sci. Bull. 53, 295-303. doi: 10.1007/s11434-007-0514-4

Liang, J., Yu, K., Wang, Y., Huang, X., Huang, W., Qin, Z., et al. (2017). Distinct bacterial communities associated with massive and branching scleractinian corals and potential linkages to coral susceptibility to thermal or cold stress. Front. Microbiol. 8:979. doi: 10.3389/fmicb.2017.00979

Mason, R. A. B. (2018). Decline in symbiont densities of tropical and subtropical scleractinian corals under ocean acidification. Coral Reefs 37, 945-953. doi: 10.1007/s00338-018-1720-z

Meron, D., Atias, E., Kruh, L. I., Elifantz, H., Minz, D., Fine, M., et al. (2011). The impact of reduced $\mathrm{pH}$ on the microbial community of the coral Acropora eurystoma. ISME J. 5, 51-60. doi: 10.1038/ismej.2010.102

Meunier, V., Geissler, L., Bonnet, S., Rädecker, N., Perna, G., Grosso, O., et al. (2021). Microbes support enhanced nitrogen requirements of coral holobionts in a high $\mathrm{CO}_{2}$ environment. Mol. Ecol. doi: 10.1111/mec.16163 [Epub ahead of print].

Mingle, J. (2020). IPCC special report on the ocean and cryosphere in a changing climate. New York review of books. 67, 49-51

Morgans, C. A., Hung, J. Y., Bourne, D. G., and Quigley, K. M. (2020). Symbiodiniaceae probiotics for use in bleaching recovery. Restor. Ecol. 28, 282-288. doi: 10.1111/rec.13069

Morrow, K. M., Bourne, D. G., Humphrey, C., Botté, E. S., Laffy, P., Zaneveld, J., et al. (2015). Natural volcanic $\mathrm{CO}_{2}$ seeps reveal future trajectories for hostmicrobial associations in corals and sponges. ISME J. 9, 894-908. doi: 10.1038/ismej.2014.188

Morrow, K. M., Moss, A. G., Chadwick, N. E., and Liles, M. R. (2012). Bacterial associates of two Caribbean coral species reveal species-specific distribution and geographic variability. Appl. Environ. Microbiol. 78, 6438-6449. doi: 10.1128/aem.01162-12

Muscatine, L., and Cernichiari, E. (1969). Assimilation of phototsynthetic products of zooxanthellae by a reef coral. Biol. Bull. 137, 506-523. doi: 10.2307/1540172

Muscatine, L., Porter, J. W., and Kaplan, I. R. (1989). Resource partitioning by reef corals as determined from stable isotope composition. Mar. Biol. 100, 185-193. doi: 10.1007/BF00391957

Neave, M. J., Apprill, A., Ferrier-Pages, C., and Voolstra, C. R. (2016). Diversity and function of prevalent symbiotic marine bacteria in the genus Endozoicomonas. Appl. Microbiol. Biotechnol. 100, 8315-8324. doi: 10.1007/s00253-016-7777-0

Neave, M. J., Rachmawati, R., Xun, L., Michell, C. T., Bourne, D. G., Apprill, A., et al. (2017). Differential specificity between closely related corals and abundant Endozoicomonas endosymbionts across global scales. ISME J. 11, 186-200. doi: 10.1038 /ismej.2016.95

Ng, T. Y., and Ang, P. (2016). Low symbiont diversity as a potential adaptive strategy in a marginal non-reefal environment: A case study of corals in Hong Kong. Coral Reefs 35, 941-957. doi: 10.1007/s00338-016-1458-4

Noonan, S., and Fabricius, K. E. (2015). Ocean acidification affects productivity but not the severity of thermal bleaching in some tropical corals. ICES J. Mar. Sci. 73, 715-726. doi: 10.1093/icesjms/fsv127

Noonan, S., Fabricius, K. E., and Craig, H. (2013). Symbiodinium community composition in scleractinian corals is not affected by life-long exposure to elevated carbon dioxide. PLoS One 8:e63985. doi: 10.1371/journal.pone.0063985

O'Brien, P. A., Morrow, K. M., Willis, B. L., and Bourne, D. G. (2016). Implications of ocean acidification for marine microorganisms from the free-living to the host-associated. Front. Mar. Sci. 3:47. doi: 10.3389/fmars.2016.00047

Pantos, O., Bongaerts, P., Dennis, P. G., Tyson, G. W., and Hoegh-Guldberg, O. (2015). Habitat-specific environmental conditions primarily control the microbiomes of the coral Seriatopora hystrix. ISME J. 9, 1916-1927. doi: 10.1038 /ismej.2015.3

Pearse, V. B., and Muscatine, L. (1971). Role of symbiotic algae (zooxanthellae) in coral calcification. Biol. Bull. 141, 350-363. doi: 10.2307/1540123

Qin, Z., Yu, K., Wang, Y., Xu, L., Huang, X., Chen, B., et al. (2019). Spatial and intergeneric variation in physiological indicators of corals in the South China Sea: insights into their current state and their adaptability to environmental stress. J. Geophys. Res. Ocean. 124, 3317-3332. doi: 10.1029/2018jc014648

Quigley, K. M., Davies, S. W., Kenkel, C. D., Willis, B. L., Matz, M. V., and Bay, L. K. (2014). Deep-sequencing method for quantifying background abundances of Symbiodinium types: exploring the rare Symbiodinium biosphere in reef-building corals. PLoS One 9, e94297. doi: 10.1371/journal.pone.0094297
Rädecker, N., Pogoreutz, C., Voolstra, C. R., Wiedenmann, J., and Wild, C. (2015). Nitrogen cycling in corals: The key to understanding holobiont functioning? Trends Microbiol. 23, 490-497. doi: 10.1016/j.tim.2015.03.008

Raina, J. B., Dinsdale, E. A., Willis, B. L., and Bourne, D. G. (2010). Do the organic sulfur compounds DMSP and DMS drive coral microbial associations? Trends Microbiol. 18, 101-108. doi: 10.1016/j.tim.2009.12.002

Raina, J. B., Tapiolas, D., Willis, B. L., and Bourne, D. G. (2009). Coralassociated bacteria and their role in the biogeochemical cycling of sulfur. Appl. Environ. Microbiol. 75, 3492-3501. doi: 10.1128/aem.02567-08

Reynaud, S., Leclercq, N., Romaine-Lioud, S., Ferrier-Pagés, C., Jaubert, J., and Gattuso, J. P. (2003). Interacting effects of $\mathrm{CO}_{2}$ partial pressure and temperature on photosynthesis and calcification in a scleractinian coral. Glob. Chang. Biol. 9, 1660-1668. doi: 10.1046/j.1365-2486.2003.00678.x

Ricke, K. L., Orr, J. C., Schneider, K., and Caldeira, K. (2013). Risks to coral reefs from ocean carbonate chemistry changes in recent earth system model projections. Environ. Res. Lett. 8:034003. doi: 10.1088/1748-9326/8/3/034003

Rodolfo-Metalpa, R., Martin, S., Ferrier-Pages, C., and Gattuso, J.-P. (2010). Response of the temperate coral Cladocora caespitosa to mid- and long-term exposure to $\mathrm{pCO}_{2}$ and temperature levels projected for the year $2100 \mathrm{AD}$. Biogeosciences 7, 289-300. doi: 10.5194/bg-7-289-2010

Schloss, P. D., Gevers, D., and Westcott, S. L. (2011). Reducing the effects of PCR amplification and sequencing artifacts on 16S rRNA-based studies. PLoS One 6:e27310. doi: 10.1371/journal.pone.0027310

Schneider, K., and Erez, J. (2006). The effect of carbonate chemistry on calcification and photosynthesis in the hermatypic coral Acropora eurystoma. Limnol. Oceanogr. 51, 1284-1293. doi: 10.4319/1o.2006.51.3.1284

Segata, N., Izard, J., Waldron, L., Gevers, D., Miropolsky, L., Garrett, W. S., et al. (2011). Metagenomic biomarker discovery and explanation. Genome Biol. 12:R60. doi: 10.1186/gb-2011-12-6-r60

Sekar, R., Mills, D. K., Remily, E. R., Voss, J. D., and Richardson, L. L. (2006). Microbial communities in the surface mucopolysaccharide layer and the black band microbial mat of black band-diseased Siderastrea siderea. Appl. Environ. Microbiol. 72, 5963-5973. doi: 10.1128/aem.00843-06

Shade, A., Jones, S. E., Caporaso, J. G., Handelsman, J., Knight, R., Fierer, N., et al. (2014). Conditionally rare taxa disproportionately contribute to temporal changes in microbial diversity. MBio 5, e01371-e01314. doi: 10.1128/ mBio.01371-14

Shenkar, N., Fine, M., Kramarsky-Winter, E., and Loya, Y. (2006). Population dynamics of zooxanthellae during a bacterial bleaching event. Coral Reefs 25, 223-227. doi: 10.1007/s00338-006-0090-0

Shiu, J. H., Keshavmurthy, S., Chiang, P. W., Chen, H. J., Lou, S. P., Tseng, C. H., et al. (2017). Dynamics of coral-associated bacterial communities acclimated to temperature stress based on recent thermal history. Sci. Rep. 7:14933 doi: 10.1038/s41598-017-14927-3

Shu, L., Kefu, Y., Qi, S., Tian-ran, C., Mei-xia, Z., and Hong-qiang, Y. (2008). Experimental study of stony coral response to the high temperature in Luhuitou of Hainan Island. Trop. Geogr. 28, 534-539. doi: 10.3969/j. issn.1001-5221.2008.06.009

Shu, L., Kefu, Y., Tianran, C., Qi, S., and Te-gu, C. (2011). Seasonal patterns of densities of symbiotic zooxanthellae in scleractinian corals from Daya Bay,northern South China Sea,and relation to coral bleaching. J. Trop. Oceanogr. 30, 39-45. doi: 10.11978/j.issn.1009-5470.2011.02.039

Singer, E., Bushnell, B., Coleman-Derr, D., Bowman, B., Bowers, R. M., Levy, A., et al. (2016). High-resolution phylogenetic microbial community profiling. ISME J. 10, 2020-2032. doi: 10.1038/ismej.2015.249

Smith, D. J., Suggett, D. J., and Baker, N. R. (2005). Is photoinhibition of zooxanthellae photosynthesis the primary cause of thermal bleaching in corals? Glob. Chang. Biol. 11, 1-11. doi: 10.1111/j.1529-8817.2003.00895.x

Steen, R. G., and Muscatine, L. (1984). Daily budgets of photosynthetically fixed carbon in symbiotic zoanthids. Biol. Bull. 167, 477-487. doi: 10.2307/1541292

Thurber, R. V., Willner-Hall, D., Rodriguez-Mueller, B., Desnues, C., Edwards, R. A., Angly, F., et al. (2009). Metagenomic analysis of stressed coral holobionts. Environ. Microbiol. 11, 2148-2163. doi: 10.1111/j.1462-2920.2009.01935.x

Tong, H., Cai, L., Zhou, G., Yuan, T., Zhang, W., Tian, R., et al. (2017). Temperature shapes coral-algal symbiosis in the South China Sea. Sci. Rep. 7:40118. doi: $10.1038 /$ srep 40118

Torda, G., Donelson, J. M., Aranda, M., Barshis, D. J., Bay, L., Berumen, M. L., et al. (2017). Rapid adaptive responses to climate change in corals. Nat. Clim. Chang. 7, 627-636. doi: 10.1038/nclimate3374 
Uthicke, S., and Fabricius, K. E. (2012). Productivity gains do not compensate for reduced calcification under near-future ocean acidification in the photosynthetic benthic foraminifer species Marginopora vertebralis. Glob. Chang. Biol. 18, 2781-2791. doi: 10.1111/j.1365-2486.2012.02715.x

Vezzulli, L., Pezzati, E., Huete-Stauffer, C., Pruzzo, C., and Cerrano, C. (2013). 16SrDNA Pyrosequencing of the Mediterranean Gorgonian Paramuricea clavata reveals a link among alterations in bacterial holobiont members, anthropogenic influence and disease outbreaks. PLoS One 8:e67745. doi: 10.1371/journal.pone.0067745

Wall, C. B., Fan, T. Y., and Edmunds, P. J. (2014). Ocean acidification has no effect on thermal bleaching in the coral Seriatopora caliendrum. Coral Reefs 33, 119-130. doi: 10.1007/s00338-013-1085-2

Wegley, L., Edwards, R., Rodriguez-Brito, B., Liu, H., and Rohwer, F. (2007). Metagenomic analysis of the microbial community associated with the coral Porites astreoides. Environ. Microbiol. 9, 2707-2719. doi: 10.1111/j.14622920.2007.01383.x

Xu, L., Yu, K., Li, S., Liu, G., Tao, S., Shi, Q., et al. (2017). Interseasonal and interspecies diversities of Symbiodinium density and effective photochemical efficiency in five dominant reef coral species from Luhuitou fringing reef, northern South China Sea. Coral Reefs 36, 477-487. doi: 10.1007/ s00338-016-1532-y

Yu, X., Yu, K., Chen, B., Liao, Z., Qin, Z., Yao, Q., et al. (2021). Nanopore long-read RNAseq reveals regulatory mechanisms of thermally variable reef environments promoting heat tolerance of scleractinian coral Pocillopora damicornis. Environ. Res. 195:110782. doi: 10.1016/j.envres.2021.110782

Yu, X., Yu, K., Huang, W., Liang, J., Qin, Z., Chen, B., et al. (2020). Thermal acclimation increases heat tolerance of the scleractinian coral Acropora pruinosa. Sci. Total Environ. 733:139319. doi: 10.1016/j.scitotenv. 2020.139319

Zhang, J., Kobert, K., Flouri, T., and Stamatakis, A. (2014). PEAR: A fast and accurate Illumina Paired-End reAd mergeR. Bioinformatics 30, 614-620. doi: 10.1093/bioinformatics/btt593

Zhang, C. C., Zhou, C. Z., Burnap, R. L., and Peng, L. (2018). Carbon/nitrogen metabolic balance: lessons from cyanobacteria. Trends Plant Sci. 23, 1116-1130. doi: 10.1016/j.tplants.2018.09.008

Zheng, X., Fuwen, K., Liu, X., Rongcheng, L., Zhidong, Z., and Xiaofeng, S. (2015). Ocean acidification does not significantly affect the calcification and photosynthesis capacity of hermatypic coral Pocillopora damicornis. Acta Oceanol. Sin. 37, 59-68. doi: 10.3969/j.issn.0253-4193.2015.10.006

Zheng, X., Wang, C., Hadi, T. A., Hadi, T. A., Ye, Y., and Pan, K. (2018). An ocean acidification-simulated system and its application in coral physiological studies. Acta Oceanol. Sin. 37, 55-62. doi: 10.1007/s13131-018-1223-3

Zhou, G., Cai, L., Yuan, T., Tian, R., Tong, H., Zhang, W., et al. (2017). Microbiome dynamics in early life stages of the scleractinian coral Acropora gemmifera in response to elevated $\mathrm{pCO}_{2}$. Environ. Microbiol. 19, 3342-3352. doi: $10.1111 / 1462-2920.13840$

Zhou, G., Tong, H., Cai, L., and Huang, H. (2021). Transgenerational effects on the coral Pocillopora damicornis microbiome under ocean acidification. Microb. Ecol. 82, 572-580. doi: 10.1007/s00248-021-01690-2

Ziegler, M., Arif, C., Burt, J. A., Dobretsov, S., Roder, C., LaJeunesse, T. C., et al. (2017). Biogeography and molecular diversity of coral symbionts in the genus Symbiodinium around the Arabian Peninsula. J. Biogeogr. 44, 674-686. doi: 10.1111/jbi.12913

Ziegler, M., Eguiluz, V. M., Duarte, C. M., and Voolstra, C. R. (2018). Rare symbionts may contribute to the resilience of coral-algal assemblages. ISME J. 12, 161-172. doi: 10.1038/ismej.2017.151

Conflict of Interest: The authors declare that the research was conducted in the absence of any commercial or financial relationships that could be construed as a potential conflict of interest.

Publisher's Note: All claims expressed in this article are solely those of the authors and do not necessarily represent those of their affiliated organizations, or those of the publisher, the editors and the reviewers. Any product that may be evaluated in this article, or claim that may be made by its manufacturer, is not guaranteed or endorsed by the publisher.

Copyright (C) 2021 Ge, Liang, Yu, Chen, Yu, Deng, Chen, Xu and Qin. This is an open-access article distributed under the terms of the Creative Commons Attribution License (CC BY). The use, distribution or reproduction in other forums is permitted, provided the original author(s) and the copyright owner(s) are credited and that the original publication in this journal is cited, in accordance with accepted academic practice. No use, distribution or reproduction is permitted which does not comply with these terms. 